\title{
Exchange Rate Misalignments and International Imbalances a FEER Approach for Emerging Countries
}

\author{
Nabil Aflouk* ${ }^{*}$, Se-Eun Jeong ${ }^{\ddagger}$, Jacques Mazier ${ }^{\S}$, Jamel Saadaoui ${ }^{\ddagger}$
}

\begin{abstract}
Since the mid-1990s, the international imbalances have increased significantly with a large US current deficit facing Asian surpluses, mainly Chinese. Since 2007, a partial reduction of these imbalances has been obtained, largely thanks to production's decreases, without large exchange rate adjustments. The Asian surpluses have remained important. The objective of this paper is to examine the exchange rate misalignments (ERM) of the main emerging countries in Asia and Latin America since the 1980s, so as to shed light on the 2000s by a long term analysis and compare with the industrialized countries' case. Our results confirm that ERM have been reduced since the mid-2000s at the world level, but the dollar remained overvalued against the East Asian countries, except the yen. Chinese, Indian and Brazilian exchange rate policies have been much contrasted since the 1980s. The Indian rupee has been more often overvalued while a more balance situation prevailed in Brazil only since the 2000s. The Latin American countries have faced wider and more dispersed ERM and current imbalances than East Asian countries. But Argentina, Chile and Uruguay benefits now of undervalued currencies while Mexico is closer to equilibrium.
\end{abstract}

JEL: F31, F32, O11

Keyword: Equilibrium Exchange Rate, Current Account Balance, Macroeconomic Balance, Emerging Countries

\footnotetext{
* PhD Student, Paris North University, CEPN-CNRS, aflouknabil@yahoo.fr

¥ Professor, College of Economics and Management, Chungnam National University, jseeun@cnu.ac.kr

$\S$ Professor, Paris North University, CEPN-CNRS, mazier@univ-paris13.fr

\$PhD student, Paris North University, CEPN-CNRS, jamelsaadaoui@gmail.com
} 


\section{$1 \quad$ Introduction}

Since the mid-1990s, the international imbalances have increased significantly with a large US current deficit facing Asian surpluses, mainly Chinese. These imbalances reflect internal disequilibrium in each area, mainly American households' over-indebtedness and the declining US competitiveness on one hand, the insufficient Chinese households' consumption on the other hand. These imbalances have been lasting, partly thanks to the financial liberalization which has facilitated their financing. The present financial crisis has been the consequence of these imbalances. Since 2007, a partial reduction of these imbalances has been obtained, largely thanks to production's decreases, without large exchange rate adjustments. However, the Asian surpluses have remained important.

Exchange rates misalignments (ERM) have been studied in details in the literature using two main approaches: the Behavioral Equilibrium Exchange Rate (BEER) and the Fundamental Equilibrium Exchange Rate (FEER). They generally concluded that the dollar was overvalued and that the euro was undervalued during the first half of the 2000s. While these misalignments have been gradually reduced, the yuan remained undervalued since the second half of the 1990s.

However less attention has been paid to emerging countries' ERM where contrasted evolutions can be observed. In most of the Asian emerging countries large current surpluses have been observed after the Asian crisis of 1997-1998. The oil producer countries have also benefited of important surpluses thanks to oil price's increase. Many countries in Latin America and in Africa have, on the contrary, suffered of current deficits, although limited. These divergent evolutions between emerging countries reflect different choices relating to growth model and exchange rate regime.

The objective of this paper is to examine the ERM of the main emerging countries in Asia and Latin America since the 1980s, so as to shed light on the 2000s by a long term analysis and compare with the case of industrialized countries.

For this purpose, a FEER approach is implemented. The FEER is defined as the level of exchange rate which allows the economy to reach the internal and external equilibriums at the same time (Williamson, 1983). The internal equilibrium is defined as the full utilization of productive resources of a country without generating inflation pressures. The external equilibrium corresponds to a sustainable current account.

In a first step, using a model of world trade, FEERs are estimated for the main currencies (the dollar, the euro, the yen, the yuan and the pound sterling). In a second step, FEERs can be estimated for each emerging country, using simple national models and linking the estimation of national FEERs to the multinational model's results to get bilateral misalignments of each currency.

Our results confirm that ERM have been reduced since the mid-2000s at the world level, but the dollar remained overvalued against the East Asian countries, except the yen. Chinese, Indian and Brazilian exchange rate policies have been much contrasted since the 1980s. The Indian rupee has been more often overvalued while a more balance situation prevailed in Brazil only since the 2000s. The Latin American countries have faced wider and more dispersed ERM and current imbalances than East Asian countries. But Argentina, Chile and Uruguay benefits now of undervalued currencies while Mexico is closer to equilibrium.

This paper is organized as follow. Section 2 summarizes the theoretical and methodological 
background. Section 3 presents the multinational model and the national model used to estimate the FEERs. Section 4 provides estimates of the external and internal equilibriums but focuses mainly on external imbalances. Section 5 presents estimates of the FEER for the main currencies and for emerging currencies. A last section concludes.

\section{Theoretical and methodological background}

ERM is defined as the gap, in percentage, between observed exchange rates and equilibrium exchange rates. Various methodologies can be used to estimate equilibrium exchange rates.

\subsection{Equilibrium exchange rates methodologies}

The PPP (Purchasing Power Parity) is the oldest one and simplest methodology to estimate equilibrium exchange rates. In order to explain movements of equilibrium exchange rates, this simple approach only relies on the relative prices. It ignores, however, other structural factors and seems too schematic, even when completed by a Balassa-Samuelson effect. Beyond the PPP hypothesis, we have two distinct methodologies to produce equilibrium exchange rates, as it is pointed in Driver and Westaway (2004), approaches based on models and approaches based on estimations. Typically, approaches based on models (complete macroeconomic models or partial equilibrium models of world trade) produce Fundamental Equilibrium Exchange Rates, initially introduced by Williamson (1983), and approaches based on econometrical estimations produce Behavioral Equilibrium Exchange Rates, firstly introduced by Clark and MacDonald (1998). In spite of several variants of FEERs (especially for the estimation of the current account target) and BEERs (for the choice of econometrical methodology and of fundamental variables), these two types of approach are used in the overwhelming majority of studies on equilibrium exchange rates. The NATREX (Stein and Allen, 1997) methodology can be seen as a variety of the BEER approach.

These two main theories of equilibrium exchange rates can be highlighted:

a) The Fundamental Equilibrium Exchange Rate and its recent developments (Cline, 2008): the FEER is defined as the exchange rate prevailing when the economy simultaneously reaches the external equilibrium (a sustainable current account determined by structural parameters) and the internal equilibrium (full utilization of the productive potential). This approach is based on a structural model which mainly describes foreign trade relations and relates explicitly movements of exchange rates to internal and external imbalances.

b) The Behavioural Equilibrium Exchange Rate is an econometric approach (Clark \& MacDonald, 1998). The BEER approach explains the exchange rate dynamic with some main variables (usually the net foreign assets, the terms of trade, the productivity and the oil prices) which influence the real exchange rate at long term. A long term equation is first estimated by a co-integration method and then, using an error correction model, a short term equation is estimated. The ERM are simply measured by the gap between the observed exchange rate and its long run value.

In a nutshell, we prefer the FEER approach because it is more explicitly articulated with the structural characteristics of each country and it ensures greater consistency of estimates across countries. But the FEER does not pretend to describe the modality of the return to the equilibrium. On the opposite, the BEER approach often suffers of too many variables added without clear justification and the long term value can hardly be regarded as an equilibrium one. 


\subsection{The FEER approach and the SMIM}

We conduct a two-step analysis (Jeong et al., 2010) in order to estimate the ERM, first at the world level for the main currencies (the dollar, the euro, the yuan, the yen and the pound sterling), second at the level of each emerging country.

First, for the main currencies, the methodology used is a synthesis of previous works on the FEER (Borowski \& Couharde, 2003; Jeong \& Mazier, 2003) and of the Symmetric Matrix Inversion Method (SMIM) recently proposed by Cline (2008). A multinational model describing the foreign trade of the main countries and of the Rest of the World is used to calculate the main currencies' equilibrium exchange rates. It is well known that in an $n$-country model there are only $n-1$ independent bilateral exchange rates, because the first country's exchange rate (usually the dollar) is the numeraire against which the others are compared. Consequently, there is an overdetermination problem in the FEER approach, as there are more equations (current account targets) than unknowns (exchange rates).

In this paper, we use the $\mathrm{n}^{\text {th }}$ country as a residual in order to solve the overdetermination problem and to ensure the consistency of the world trade in volume and in value. Exports and imports of the residual country are calculated as residual of the world trade equilibrium in constant and current prices. To avoid such an asymmetric approach and following the SMIM approach, the six countries or areas (the United States, China, Japan, the United Kingdom, the Euro area and the Rest of the World) will be treated symmetrically by carrying out six sets of estimates with six multinational models where each country is treated successively as a residual. Instead of a simple average of the results, the solution adopted in this paper will be to use (as the estimate of the FEERs) the average of equilibrium exchange rates obtained from all the solutions, except the one for which the country in question is regarded as a residual (designated OCI for own country included).

For each emerging country, an equilibrium exchange rate will be estimated using a simple national model of foreign trade. The equilibrium exchange rate will be defined, as previously, as the exchange rate compatible with the internal and external equilibriums of each country. It has been shown that, for a relatively small country, a national model gives results very close to the ones obtained with a multinational model where the studied country would be explicitly described (Jeong \& Mazier, 2003).

Lastly, based on studies of the medium-term determinants of current accounts (Faruqee \& Isard, 1998; Chinn \& Prasad, 2003), the equilibrium current account are determined by estimating structural determinants of current account (the demographic features, the developmental stage, the public deficit, the net foreign assets, etc...) relying on panel regression techniques.

\section{$3 \quad$ Macroeconomic modeling}

\subsection{The multinational model}

The model describes the trade structure of the main countries or areas, namely, the United States, Japan, China, the Euro area, the United Kingdom and the Rest of the World using standard foreign trade equations: export and import volume equations, export and import price equations. Each country is successively treated as a residual and in that case export and import volumes are determined as residual of the equations of world trade equilibrium in value and in volume while their export and import prices are determined in the same manner as for other trading partners. We notice that this multinational specification gives a full account of 
interdependent effects in volume and prices of exports and imports of all countries. We incorporate a consumer prices equation to take into account the feedback effect between the consumer prices and the import prices. The real effective exchange rate is defined relatively to the consumption prices. Finally, the current account is defined as the trade balance augmented of debt service.

In this framework, the FEERs are defined as the real effective exchange rates compatible with the simultaneous realization of the internal and external equilibriums at medium term of each trading partner. The internal equilibrium means that actual output follows the potential output and the external equilibrium means that actual current account corresponds to the sustainable current account at medium term.

On the whole, each multinational model comprises 35 endogenous variables $(x, m, p x, p m, p d$ for the six countries or areas and the five bilateral exchange rates $e$ ) for 35 equations $(x, m, b$ for the five countries other than the residual one, $p x, p m, p d$ for the six countries and the two world trade equilibrium equations). The real effective exchange rates are calculated ex post using bilateral exchange rates and consumer prices.

\subsection{The national model}

For each emerging country, except China, it is possible to estimate an equilibrium exchange rate using a foreign trade model in which the world demand and the world trade prices are exogenous. As explained above, it is not necessary for a relatively small country at the world scale to use a multinational model to estimate equilibrium exchange rates. The equations specify the trade volume and price equations for a small country facing world economy (the model is given in appendix 1). Solving this simplified model in logarithmic differential form gives $r$, the misalignment in real effective terms:

$$
r_{i}=\left[\frac{\left(\left(b_{i} /\left[\mu_{i} T_{i}\left(1-\sigma_{\text {petxi }}-\sigma_{x i}\right)\right]\right)+\eta m_{i} d i_{i}-\eta x_{i} d_{i}^{*}\right)}{\left(\left(1-\alpha x_{i}\right) \varepsilon x_{i}+\varepsilon m_{i} \alpha m_{i}+\alpha x_{i}-\alpha m_{i}\right)}\right]
$$

Where $b$ is the difference between the observed current account and the equilibrium one, as percentage of GDP, $d^{*}$ is the world demand in volume and $d i$ is the internal demand in volume, written in logaritmic differential compared with the equilibrium, $\sigma_{p e t x}=E P_{p e t} M_{p e t} / P X X$ is the ratio of net oil imports on non-oil exports and $\sigma_{x}=i E F / P X X$ is the ratio of foreign debt service on non-oil exports, $\mu$ the openness ratio and $T$ the ratio of export to import.

The FEER approach focuses on the real effective exchange rates. However, the nominal bilateral exchange rate against the dollar of each currency can be more intelligible. We can find out $e$, the degree of misalignment in bilateral nominal term; the partner countries' misalignments are given by the previous multinational model:

$$
e_{i}=r_{i}-\sum_{j \neq i} \lambda_{i j}\left(p x_{j}-e_{j}\right)
$$

We can also compute the effective ERM based on consumer prices:

$$
r c_{i}=\left(1-\alpha m_{i} \mu_{i}\right) r_{i}+\sum_{j \neq i} v_{i j}\left(p d_{j}-e_{j}\right)-\sum_{j \neq i} \lambda_{i j}\left(p x_{j}-e_{j}\right)
$$

Where $p x$ is the global export price and $p d$ is the consumer price. 


\subsection{Foreign trade elasticities}

Without doing original econometric work, trade equations are taken from existing estimations realized with specifications close to the standard model presented before. We use especially long-term elasticities. The main results are presented in appendix 2 . Considering the uncertainty surrounding estimations, sensitivity tests to elasticity modifications are provided in appendix 3 . The sensitivity to volume and price elasticities appears to be limited.

\section{$4 \quad$ External and internal equilibrium at medium term}

\subsection{Estimation of equilibrium current account}

As current account equals the difference between domestic saving and investment, the current account equilibrium is examined from the perspective of the medium and long run determinants of saving and investment behaviors (Faruqee \& Isard, 1998; Chinn \& Prasad, 2003). According to these authors, the main determinants of the current account at medium term are: the demographic characteristics, such as, the dependency ratios of dependent populations relative to the working age population, which is expected to exert a negative influence, with a higher dependency ratio leading to more spending; the net foreign asset, which is expected to have a positive effect, due to the capital income resulting from it; the government budget balance, with a public deficit having a negative effect on the current account, but this effect may be regarded as a simple accounting one ${ }^{1}$ which should not to be introduced. Finally, we introduce the output gap, since a higher utilization of production capacity leads to a deterioration of the current account.

The equations of current account are estimated with panel data for 1980-2003 period and for two groups of countries. In a medium term perspective, we use non-overlapping four years average of annual data in order to estimate medium run current account in which cyclical components have been washed out (Lee et al., 2008). Prolonged recession or boom can be observed over a period of four years in many countries, especially in the emerging countries where macro instability is greater. In order to estimate medium to long run trend of current account, we set the output gap at zero in the simulation of the current account.

The variables of equation [4] are defined as follows: $C A$, current account as \% of GDP; ISNFA, initial stock of net foreign assets at the beginning of each period of 4 years as \% of GDP; $C D R$, child dependency ratio, population under the age of 15 years as $\%$ of population aged 15 to 64; $O D R$, old dependency ratio, population over the age of 65 years as $\%$ of population aged 15 to $64 ; O G$, output gap in $\%$ of the potential production. The sources of the different variables are presented in appendix 4.

$$
C A_{i t}=\alpha_{i}+\alpha_{t}+\beta_{0}+\beta_{1} I S N F A_{i t}+\beta_{2} C D R_{i t}+\beta_{3} O D R_{i t}+\beta_{4} O G_{i t}+\varepsilon_{i t}
$$

One group is composed of 19 industrial countries (Australia, Austria, Canada, Denmark,

\footnotetext{
${ }^{1}$ There are other variables, such as the openness ratio, which plays negatively, a higher openness meaning a greater possibility of assuring the debt service in the future, or the relative real GDP per capita, which exerts a non linear influence according to stages of development. We tried these variables, but results were not significant enough. Moreover, relative GDP per capita is evaluated non stationary by most of tests.
} 
Finland, France, Germany, Ireland, Italy, Japan, Netherlands, New Zealand, Norway, Portugal, Korea, Spain, Sweden, the United Kingdom and the United States) and will be used for determining the current account targets of the United States, Japan, the Euro area, the United Kingdom and Korea.

The other group, composed of 26 emerging economies (Algeria, Argentina, Bolivia, Brazil, Chile, China, Colombia, Ecuador, Egypt, India, Indonesia, Malaysia, Mexico, Morocco, Pakistan, Paraguay, Peru, Philippines, Singapore, Sri Lanka, Thailand, Tunisia, Turkey, Uruguay, Venezuela and Vietnam), will be used for determining the current account target of China and other emerging countries ${ }^{2}$.

The results of unit root tests are presented in appendix 5. As it can be seen, we reject the null hypothesis of non-stationarity in all the series by using the IPS test statistic (2003).

For industrialized countries, the estimated coefficients of equation [4] are on the whole significant with the predicted signs (Table 1) in different specifications. The dependency ratios are not highly significant, although they are the best theoretically justified variables. Output gap turns out to have negative effects on current account. Country effects raise the determination ratio and reflect the existence of strong specificities between this large set of industrial countries. Time fixed effects are less relevant and contribute to deteriorate the quality of the estimation. On the whole the panel specification with country fixed effects seems the most relevant due to the prevailing specificities between the set of countries and is adopted in order to calculate the equilibrium current account.

Table 1. Determinants of the current account for industrialized countries

\begin{tabular}{cccc}
\hline & OLS Pooled & Individual Fixed Effects & Time Fixed Effects \\
\hline Constant & $6.69 * *$ & $11.27 * * *$ & 0.69 \\
& $(2.14)$ & $(3.29)$ & $(0.29)$ \\
Initial Stock of Net & $0.06^{* * *}$ & $0.02 * *$ & $0.07 * * *$ \\
Foreign Assets & $(10.87)$ & $(2.22)$ & $(8.51)$ \\
Child Dependency & $-0.16^{* *}$ & $-0.26^{* * *}$ & 0.00 \\
Ratio & $(-2.23)$ & $(-4.18)$ & $(0.02)$ \\
Old Dependency & -0.09 & $-0.19 * *$ & -0.03 \\
Ratio & $(-1.32)$ & $(-2.28)$ & $(-0.51)$ \\
Output Gap & $-0.31 * * *$ & $-0.47 * * *$ & $-0.51 * * *$ \\
Adjusted $R^{2}$ & $(-2.82)$ & $(-5.77)$ & $(-4.09)$ \\
\hline Number of & 0.47 & 0.89 & 0.56 \\
Observations & 114 & 114 & 114 \\
\hline
\end{tabular}

(Source: authors' estimates)

$(()=\mathrm{T}$ statistics; $* * *=$ significant at $1 \%, * *=$ significant at $5 \%, *=$ significant at $10 \%)$

(Coefficients robust to heteroskedasticity)

\footnotetext{
${ }^{2}$ For the calculation of the equilibrium current account for industrial and emerging countries, we follow an "in sample approach". The country for which the equilibrium current account is calculated is always included in the panel estimation. This approach is in opposition to the "out of sample" method where the country, for which the equilibrium current account is computed, is excluded from the panel estimation (Korhonen and Ritola, 2009). Especially, China is part of the multinational model with the main developed countries, but its current account equilibrium is based on a panel estimation including China and the other emerging countries.
} 
Results for emerging countries are less conclusive than those for industrial countries, as in the case of other empirical studies (Chinn \& Prasad, 2003). The specification has been slightly modified on two points. A single dependency ratio (DR) with both child and old population is used instead of two separate ones. Life expectancy is smaller in emerging countries and makes the old dependency ratio less relevant. The oil products balance (OB) has a larger impact on emerging countries' current account and is introduced as a new explaining variable. Increasing oil prices improve oil producers' current accounts and deteriorate other emerging countries' current accounts. The coefficients are on the whole significant with predicted signs in the different specifications (Table 2). A comparison of the specifications for industrial and emerging countries with the same variables show that the results (for emerging countries with the specification used for industrialized countries) are close from other studies (Jeong et al., 2010). Country effects raise the determination ratio and reflect strong specificities between the emerging countries. Like previously, the panel specification with country fixed effects seems the most relevant and is adopted in order to calculate the equilibrium current account.

Table 2. Determinants of current account for emerging countries

\begin{tabular}{|c|c|c|c|}
\hline & OLS Pooled & Individual Fixed Effects & Time Fixed Effects \\
\hline Constant & $\begin{array}{c}8.78 * * * \\
(6.62)\end{array}$ & $\begin{array}{c}14.23 * * * \\
(7.11)\end{array}$ & $\begin{array}{c}3.85 * * * \\
(2.79)\end{array}$ \\
\hline $\begin{array}{c}\text { Initial Stock of Net } \\
\text { Foreign Assets }\end{array}$ & $\begin{array}{c}0.07 * * * \\
(9.88)\end{array}$ & $\begin{array}{c}0.06 * * * \\
(6.20)\end{array}$ & $\begin{array}{c}0.07 * * * \\
(11.90)\end{array}$ \\
\hline Dependency Ratio & $\begin{array}{c}-0.11 * * * \\
(-5.45)\end{array}$ & $\begin{array}{c}-0.20 * * * \\
(-6.67)\end{array}$ & $\begin{array}{l}-0.03 \\
(-1.60)\end{array}$ \\
\hline Oil Balance & $\begin{array}{c}0.21 * * * \\
(6.35)\end{array}$ & $\begin{array}{c}0.22 * * * \\
(2.65)\end{array}$ & $\begin{array}{c}0.19 * * * \\
(6.27)\end{array}$ \\
\hline Output Gap & $\begin{array}{l}-0.39 * * \\
(-2.49)\end{array}$ & $\begin{array}{l}-0.37 * * \\
(-2.49)\end{array}$ & $\begin{array}{l}-0.32^{*} \\
(-1.86)\end{array}$ \\
\hline Adjusted $R^{2}$ & 0.50 & 0.57 & 0.60 \\
\hline $\begin{array}{c}\text { Number of } \\
\text { Observations }\end{array}$ & 156 & 156 & 156 \\
\hline
\end{tabular}

\subsection{The simulated equilibrium current balances}

For simulating equilibrium current balances, we use the value of initial stocks of net foreign asset at the beginning of each four years period's and four years average values of dependency ratios and other variables, but we exclude output gap in order to remove short-term effects. Figures 1 to 3 show the observed and equilibrium values of the current account for the main emerging countries.

A last correction should be specified. In the FEER theoretical framework, the whole difference between observed current balance and equilibrium one must not be interpreted entirely as an external disequilibrium. This difference is partly due to delayed effects of exchange rates variations that have not yet occurred entirely, but should be taking into account in the estimation. This correction is made using the dynamic structure of external trade equations. These figures show observed and adjusted current accounts with equilibrium ones. 
Figure 1: Actual and equilibrium current accounts of China, India and Brazil
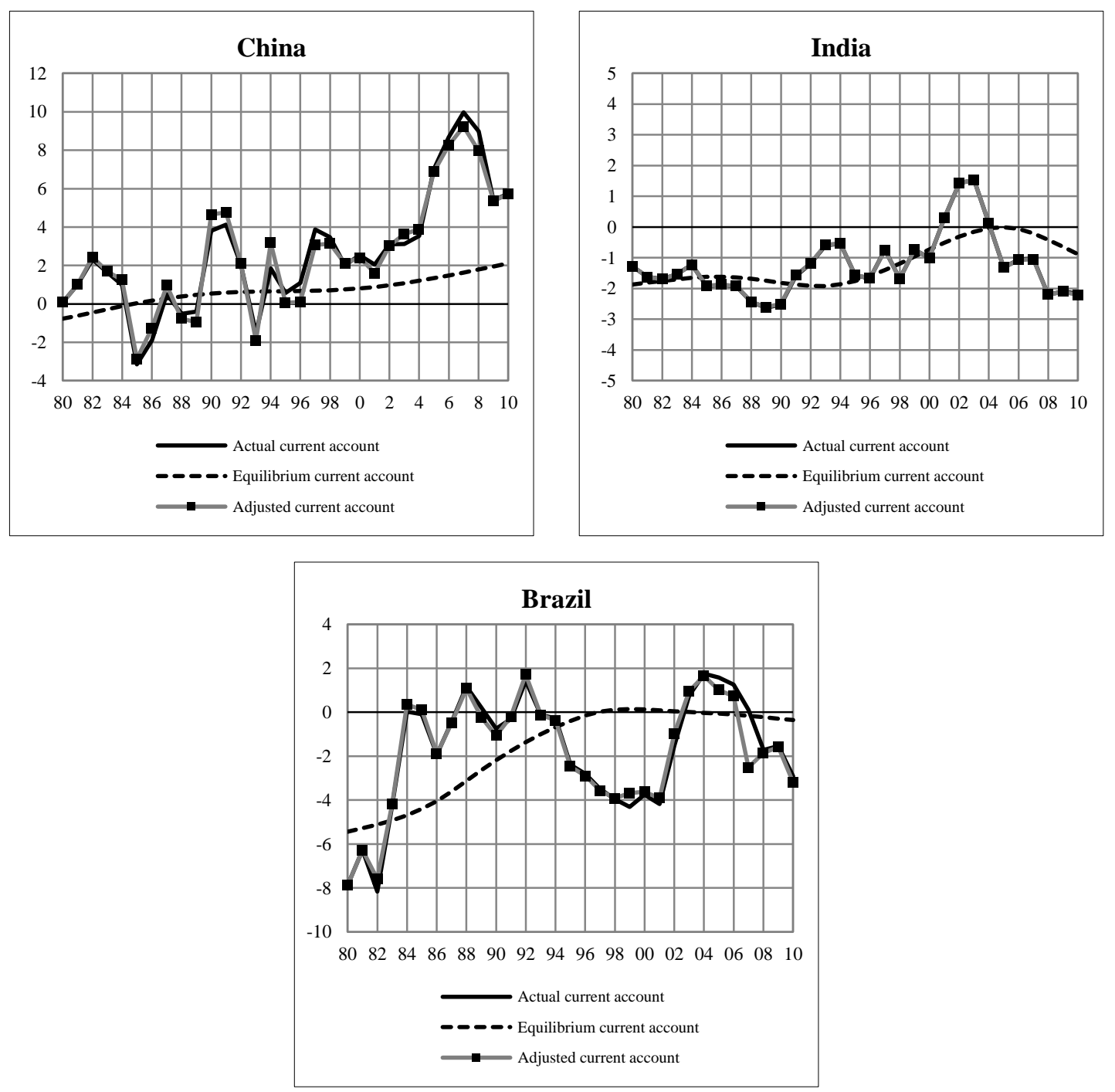

(Source: authors' calculation, International Monetary Fund (World Economic Outlook, April 2010) for the observed current account as \% of GDP, forecast for 2010)

The BRICs ${ }^{3}$, the most important emerging countries, are interesting to compare together because they have faced contrasted evolutions (figure 1). First, China had an equilibrium current account close to zero \% of GDP during the 1980s and the first years of 1990s, which seems coherent with the policy adopted by Chinese authorities that wanted to avoid the resort to large external debt. The structural reforms, which started in 1979, have allowed a progressive openness to foreign trade while the productive sector was modernized. During the 1990s the openness has accelerated with large inflows of foreign direct investments. Since the mid-1990s, the equilibrium current account has increased to reach $2 \%$ of GDP in 2008. In this evolution the improvement of net external position and the decreasing of the dependency ratio played a positive role. On the whole Chinese surpluses have become larger after the second half of the 1990s in spite of the impact of the Asian crisis after 1998.

\footnotetext{
${ }^{3}$ Among the BRICs, Russia is not examined in our paper due to strong specialization in commodities and to statistical problems during the transition period.
} 
Second, in India economic reforms have been more limited than in China (Chauvin \& Lemoine, 2005). However accelerated growth and increasing imports have induced large current deficits, which reflects a very different economic strategy compared with China. At the beginning of the 2000s, the improvement of the current account was mainly explained by a slowdown with decreasing imports and by rising prices of agricultural exports. It didn't last and the growth recovery combined with the increase of oil prices induced a new huge deficit after 2005 . The current account equilibrium, largely negative during the 1980s, increased progressively to reach zero $\%$ of GDP at the middle of the 2000s, mainly thanks to the improvement of the net external position and of the dependency ratio. At the end of the 2000s, the equilibrium current account decreased to $-1 \%$ of GDP due to a degradation of the net external position.

Third, Brazil is a last case as current deficits have been far larger than in China and India at the beginning of the 1980s (around -8\% of GDP, before the debt crisis) and in the second half of the 1990s (-4\% of GDP, after the success of the Plan Real and the large flow of foreign direct investments). The equilibrium current account was highly negative at the beginning of the 1980s (-6\% of GDP), which reflected a growth strategy based on foreign debt, quite different from the Chinese and even Indian cases. But it increased regularly up to a level close to $0 \%$ in the 2000s, mainly thanks to the decline of the dependency ratio.

\section{Figure 2: Actual and equilibrium current accounts of East Asian countries}

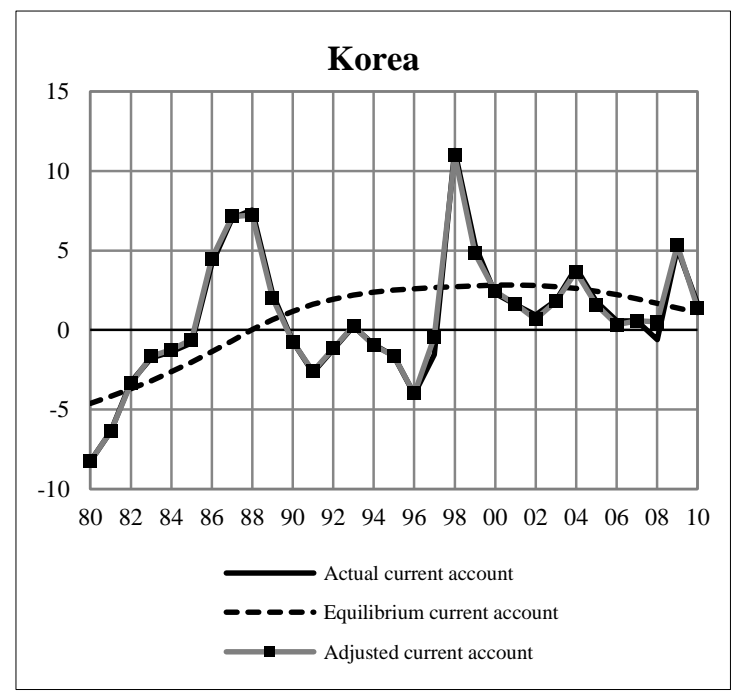

South Korea presents some similar features with the Japanese case with large current surpluses in the second half of the 1980s and after the Asian crisis of 1997. The equilibrium current account has increased a lot since the 1980s, from around -5\% of GDP up to $1 \%$ in the 1990s, thanks to its increasing net external position and a moderate declining dependency ratio. During the 2000s the Korean current account remained close to its equilibrium value (figure 2).

The South East Asian countries present some similarities (figure 2). During the 1980s and especially during the 1990s before the financial crisis of 1997-1998, their current accounts have often been inferior to their equilibrium values which were close to 0\% of GDP in Indonesia and Malaysia and negative, but increasing thanks to the decrease of the dependency ratios, in Thailand and Philippines. High rates of growth and the resort to foreign debt and FDI can explain this configuration. After the Asian crisis and the large devaluations that followed, the East Asian countries have accumulated important current surpluses with the export booms. During the 2000s these surpluses have decreased, especially in Thailand and, to a less extent, 
in Indonesia. On the whole, the current accounts remained higher than the equilibrium values which were close to $0 \%$ of GDP. In Malaysia and Philippines the current surpluses were larger, but with increasing equilibrium values due the improvement of their net foreign positions, especially in Malaysia.
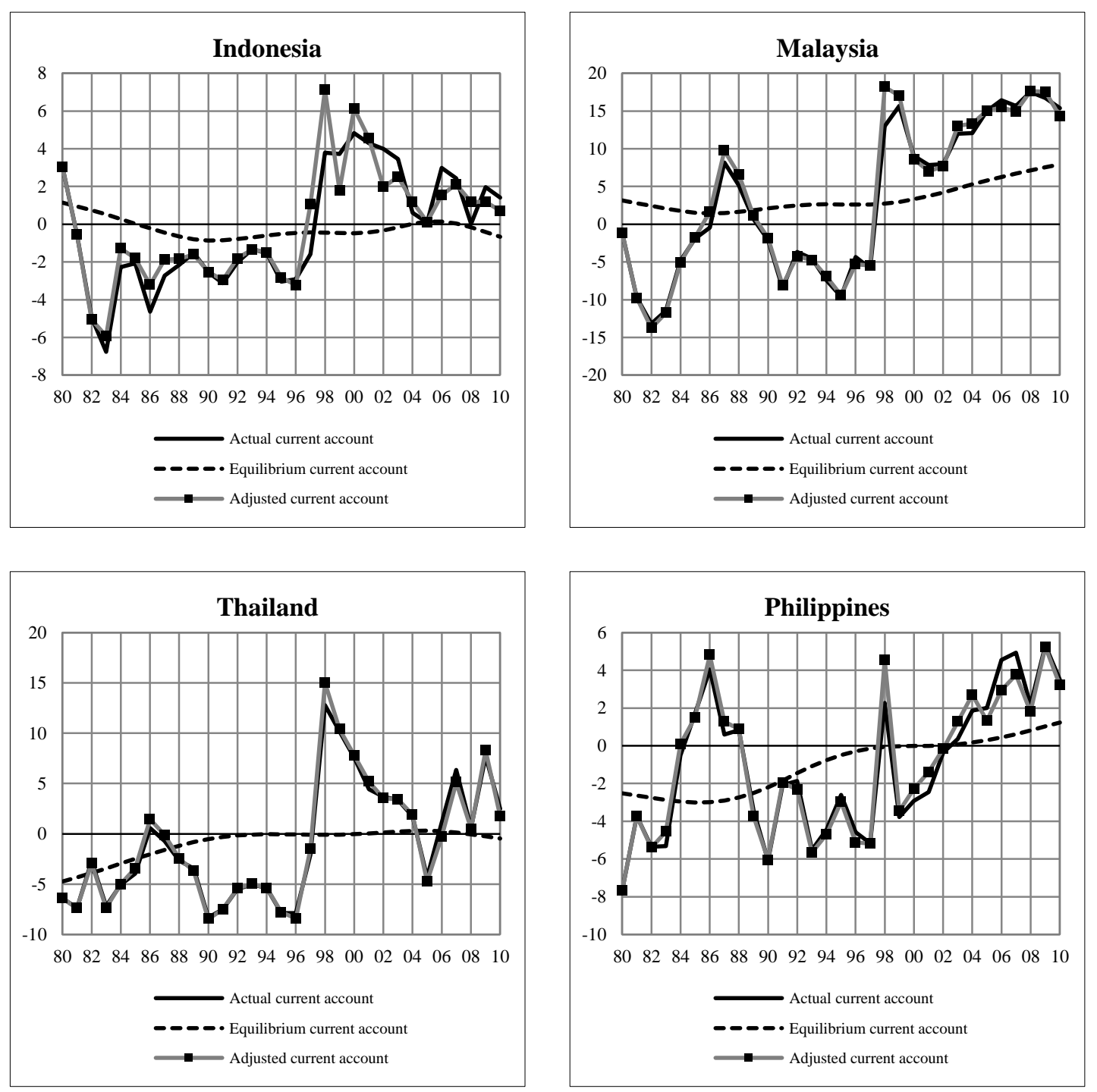

(Source: authors' calculation, International Monetary Fund (World Economic Outlook, April 2010) for the observed current account as \% of GDP, forecast for 2010)

The current account imbalances of Latin American countries are larger and more frequent than those observed in East Asia (figure 3). In Mexico and Colombia, after the debt crisis of 1982 and the following devaluations, the current surpluses didn't last. Deficits reappeared and remained during the 1990s and 2000s, largely under the current account equilibrium. These equilibrium values increased sharply from $-5 \%$ at the beginning of the 1980 s up to $0 \%$ at the end of the 2000s due to the decline of the dependency ratio and to the rising oil prices during the 2000s, especially in the Mexican case.

Argentina is a case study. The 1980s were marked by chaotic evolutions with high inflation, recurrent depreciation, current deficits and a succession of stabilization plans which failed and led to the adoption of the currency board in 1991. During the 1990s current deficits enlarged 
up to -5\% of GDP, well under the equilibrium value, until the crisis of 2002 and the end of the currency board. The production's decline and large depreciation then induced a huge current surplus which declined after, but remained above the equilibrium value close to 0\% of GDP in the 2000s. The increase of the current account equilibrium in Argentina since the 1980s has resulted of two opposite trends, a favorable evolution of the dependency ratio and the rising oil net exports on one hand, a deterioration of the net foreign assets on the other, which led to stabilization around $0 \%$ of GDP.

Figure 3: Actual and equilibrium current accounts of Latin American countries
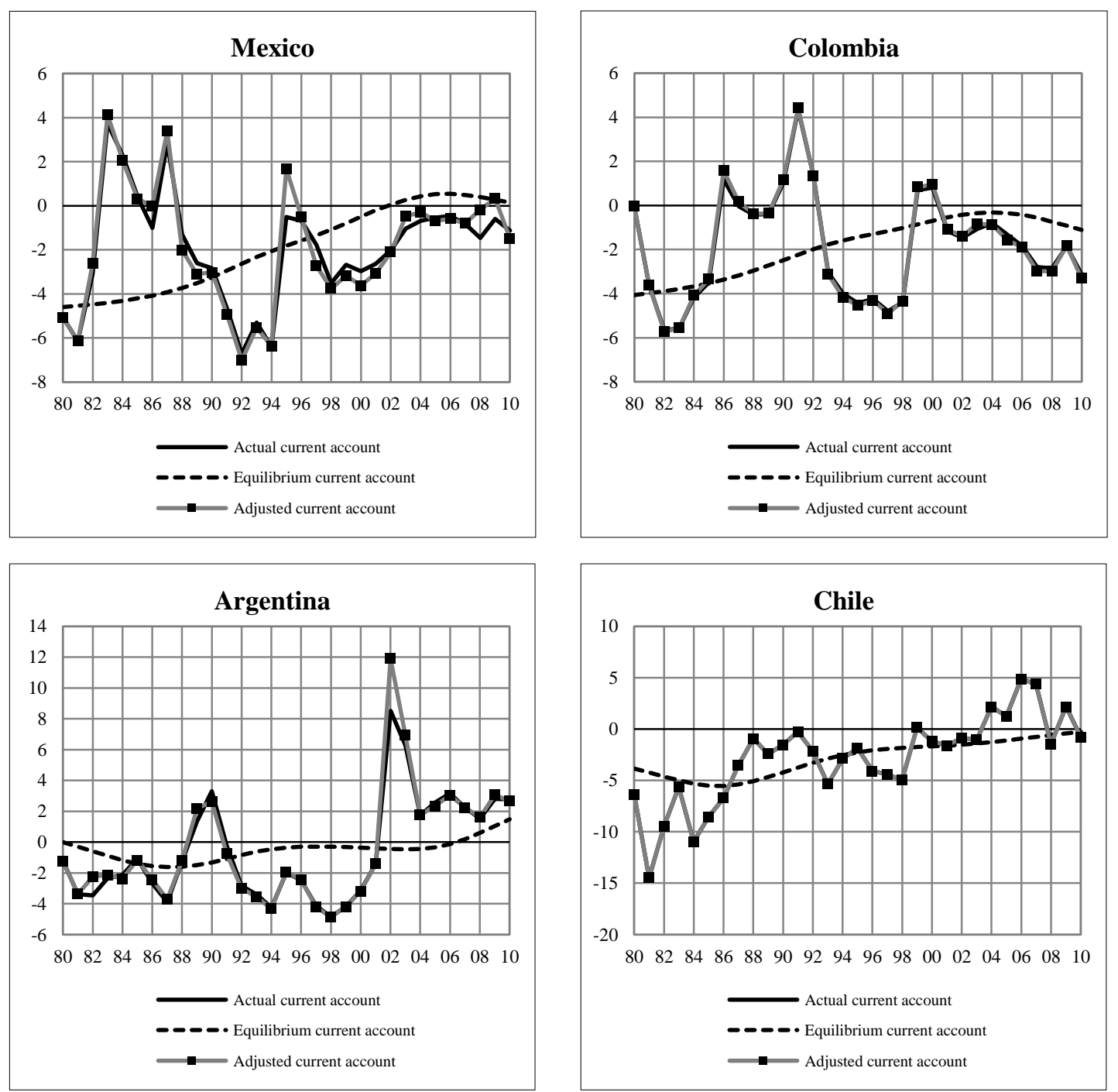

(Source: authors' calculation, International Monetary Fund (World Economic Outlook, April 2010) for the observed current account as \% of GDP, forecast for 2010)

The beginning of the 1980s was marked in Chile, like in many Latin American countries, by successive anti-inflation plans in a context of uncertainty following the Mexican crisis of 1982. Huge current deficits (around -10\% of GDP) characterized that period but were progressively reduced in the middle of the 1980s when Chile recovered a steady and more sustainable growth. Except during the mess provoked by the Asian and Russian crisis in 1997-1998, current account improved and led to increasing surpluses in the 2000s. The equilibrium current account appears in line with this trend, permanently negative but increasing from -4\% of GDP in 1980 to $-2 \%$ in the 2000s. The decline of the dependency ratio and the improvement of the net foreign position explain this evolution. 


\subsection{The estimation of internal equilibrium}

The internal equilibrium is defined as the state of full utilization of productive resources, without inflation pressures. For sake of simplification, a restrictive approach, limited to the measure of the potential output, is adopted. This approach of internal equilibrium seems less suited for emerging countries like China or Brazil, where the concepts of potential output and full employment raise many problems, particularly because of the extent of regional imbalances and hidden underemployment in rural areas (Bouveret et al., 2006). This estimation of output gap is simply taken as representative of the degree of deviation of the internal demand $(d i)$. It must be regarded as a first step. It seems, however, sufficient at this stage mainly because results are only slightly sensitive to output gap's estimates, as we shall see below.

Different methods can be employed in calculating potential production and the corresponding output gap. For industrialized countries, we take the values estimated with production function by the $\mathrm{OECD}^{4}$. This approach relies on estimated productions functions and a measure of the available productions factors in the country. It demands more information and more hypotheses regarding economic mechanisms than other simpler approaches, but is less mechanical and is theoretically more relevant.

For developing countries, this kind of estimates is not available. So we calculate output gap by using the Hodrick-Prescott filter on real GDP over the period 1970-2015 ${ }^{5}$. However, a study in depth on this issue found that output gaps of East Asian countries estimated by several methods are similar for the period 1975-2000 (Gerlach \& Yiu, 2004). In addition, our sensitivity tests show that errors in output gap estimation do not disrupt the whole conclusion. In the case of China, an increase of $1 \%$ in output gap leads to an increase of less than $1 \%$ of undervaluation.

\section{$5 \quad$ Equilibrium exchange rates and misalignments}

Although the methodology is basically the same, equilibrium exchange rates and misalignments are not estimated in the same way for all the countries. For the main economic partners (the U.S.A., China, the Euro area, the U.K., Japan and the Rest of the World), with the internal and external equilibriums previously estimated, the multinational model is used six times to produce misalignments in terms of real effective exchange rates $r=d \log R=d R / R=\left(R-R^{e}\right) / R^{e}$ and nominal exchange rate against the dollar $e=d \log E=d E / E=\left(E-E^{e}\right) / E^{e}$, each country playing successively the role of residual country without its own current account target. The final solution is obtained by making an average of the 5 runs in which the current account target of each country is included (designated OCI for own country included). This allows determining under-valuations ( $e>0$ and $r>0$ ) or overvaluations $(e<0$ and $r<0)$ for the dollar, the euro, the yen, the yuan, the pound sterling and the Rest of the World's currency over the period 19822010.

For the other countries, Korea, India, Brazil, the other East Asian and Latin American countries, a simple national model is used for each country and linked to the results of the multinational model to obtain misalignments in terms of real effective exchange rates (using relative consumption prices) and nominal exchange rate against the dollar.

For all the emerging countries examined, the following figures show the evolution of the observed and equilibrium exchange rate over the period 1982-2010, in real effective and

\footnotetext{
${ }^{4}$ Economic Outlook, OECD, May 2010.

${ }^{5}$ As it is known, this filter has certain disadvantages. It does not define well the output gap at the beginning and at the end of samples. It tends to neglect the structural breaks and the regime shifts. For prolonged slowdowns it deviates too much from a production function gap. We use the Hodrick-Prescott filter with a lower smoothing parameter than that of industrialized countries to take into account that the business cycle is shorter in emerging countries.
} 
nominal bilateral against the dollar terms. For all the countries, including the USA, the euro area and Japan, tables 5 and 6 in appendix 6 give the under (over)valuation in real effective $(r)$ and nominal bilateral terms $(e)$ over the same period. A comparison is also made with other approaches in appendix 7. Our results are globally convergent with those of Cline \& Williamson (2008, 2009 and 2010) with some few divergences which can be explained by differences in the equilibrium current account for few countries.

Results are presented in two steps. First, a general assessment of the exchange rate misalignments is proposed using a set of potential explanatory variables. Three kinds of variables appear especially relevant, the degree of openness, the type of international specialization and the exchange rate regime linked to the degree of financial liberalization. These results lead to distinguish, in a second step, three groups of countries, the BRICs (except Russia) as the main emerging countries with smaller degree of openness, the East Asian countries more specialized in manufacturing products and with exchange rate regimes more frequently anchored on the dollar and, last, the Latin American countries with more often flexible exchange rate regimes and increasing capital account openness.

\subsection{A general assessment of exchange rate misalignments}

At first glance, exchange rate misalignments may seem to follow rather diverging paths. Actually, panel unit root tests conducted on the series of misalignments for the 17 countries on the 1982-2008 period show that these series simply follow a stationary process. Furthermore, exchange rate misalignments, measured in absolute value, can be explained by three groups of variables.

- First, the degree of openness, measured as the half-sum of export and import in percentage of the GDP, has a negative impact on the misalignments. Indeed higher trade openness increases the impact of a variation of price competitiveness on current account. Consequently, a smaller variation of exchange rate is necessary to reach the external equilibrium, which implies smaller misalignments.

- Second, the nature of international specialization has a strong influence on the misalignments' amplitude. This can be described through two kinds of indicators, the comparative advantage in manufactured goods on one hand, the regional specialization on the other. Higher comparative advantages in manufactured goods, like in many East Asian countries, mean stronger constraints on firms to preserve competitiveness, compared with the case where international trade is more specialized in raw materials, like in many Latin American countries. This external constraint limits the amplitude of exchange rate misalignments which can be supported at medium term. As a consequence, a negative relation is expected between manufacturing comparative advantage and misalignment. Regional specialization, measured as the share of exports towards the regional area (East Asia, South America and North America) in percentage of total exports, is another explaining variable of misalignments, also with a negative impact. Stronger regional integration implies more price competition, which limits misalignments.

- Third, exchange rate regime, combined with the degree of financial liberalization, is the last set of explaining variables. In a simplified approach, the IMF de jure classification between fixed, intermediate and floating regimes can be used. Fixed exchange rates regime leads to larger misalignments. Conversely, floating regime limits misalignments. If a value of +1 is given to fixed regimes, zero to intermediate ones and -1 to floating regimes, a positive relation is expected between the exchange rate regime indicator and the amplitude of misalignment. The 
relative financial openness, based on a de jure measure of capital account openness (the ChinnIto index, 2008), is the second relevant factor. Higher financial liberalization facilitates monetary adjustments, which reduces exchange rates misalignments, while capital controls have the opposite effect. A negative relation is therefore expected between the financial openness indicator and misalignment. Last, the two previous variables, the exchange rate regime indicator and the financial openness, can be combined in a single indicator with a positive impact, as their interaction can reinforce each other. A floating regime with financial liberalization leads to smaller misalignments, while a fixed regime combined with financial liberalization, like in Argentina during the 1990s, induces large misalignments.

On the whole, equation [5] summarizes the different determinants of exchange rate misalignments with the variables defined as follow: $A E R M$, absolute exchange rate misalignment in real effective terms; OPEN, trade openness measured as the half sum of export and import in percentage of GDP; $A C R M A N$, indicator of comparative advantage in manufactured goods, given by the CHELEM databank; XREG, indicator of regional specialization, equal to the share of exports towards the associate region, in percentage of total exports; $E R R$, exchange rate regime indicator, equal to +1 for fixed regime, 0 for intermediate one and -1 for floating one, according to the de jure IMF classification; RKAOPEN, relative financial openness, compared with the weighted world average and based on the Chinn-Ito index (2008).

$$
\begin{aligned}
& A E R M_{i t}=\gamma_{i}+\gamma_{t}+\delta_{0}+\delta_{1} \text { OPEN }_{i t}+\delta_{2} A_{C R M A N_{i t}}+\delta_{3} X_{R E G_{i t}}+\delta_{4} E R R_{i t}+\delta_{5} R K A O P E N_{i t} \\
& +\delta_{6} E_{R R} * R K A O P E N_{i t}+\varepsilon_{i t}
\end{aligned}
$$

The equation is estimated with panel data on the 1982-2008 period for the whole emerging and industrial countries. The results of unit root tests are presented in appendix 8. The null hypothesis of the presence of unit root is rejected for all the series, except for the trade openness (OPEN) and the comparative advantage indicator (ACRMAN), which must be written in first difference in theory. The estimated coefficients of equation [5] are given in table 3. They are all significant with the predicted signs. Country fixed effects estimates are not presented. They don't improve the quality of the adjustment, mainly because countries' specificities are already present in the explanatory variables.

Beyond these first results on the determinants of exchange rate misalignments, analysis can be developed at the level of three groups of countries rather homogenous by their characteristics, the BRICs (Brazil, India and China) as the largest emerging countries with smaller degree of openness, the East Asian countries more specialized in manufactured products and, last, the Latin American countries with more often flexible exchange rate regimes and increasing capital account openness. 
Table 3: Determinants of the real effective misalignments in absolute value

\begin{tabular}{|c|c|c|}
\hline & OLS Pooled & OLS Pooled \\
\hline Constant & $\begin{array}{c}0.24 * * * \\
(34.93)\end{array}$ & $\begin{array}{l}0.15^{* * *} \\
(35.94)\end{array}$ \\
\hline$O P E N$ & $\begin{array}{l}-0.34 * * * \\
(-20.11)\end{array}$ & - \\
\hline$\triangle(O P E N)$ & - & $\begin{array}{c}-0.26 * * * \\
(-4.67)\end{array}$ \\
\hline$A C R M A N$ & $\begin{array}{c}-0.0008 * * * \\
(-19.10)\end{array}$ & - \\
\hline$\Delta(A C R M A N)$ & - & $\begin{array}{c}-0.001 * * * \\
(-6.28)\end{array}$ \\
\hline$X R E G$ & $\begin{array}{c}-0.09 * * * \\
(-5.79)\end{array}$ & $\begin{array}{c}-0.03 * * * \\
(-3.13)\end{array}$ \\
\hline$E R R$ & $\begin{array}{c}0.04 * * * \\
(9.36)\end{array}$ & $\begin{array}{c}0.03 * * * \\
(17.50)\end{array}$ \\
\hline RKAOPEN & $\begin{array}{c}-0.01 * * * \\
(-6.80)\end{array}$ & $\begin{array}{c}-0.009 * * * \\
(-6.35)\end{array}$ \\
\hline$E R R * R K A O P E N$ & $\begin{array}{c}0.01 * * * \\
(6.97)\end{array}$ & $\begin{array}{c}0.02 * * * \\
(19.50)\end{array}$ \\
\hline Adjusted $R^{2}$ & 0.82 & 0.91 \\
\hline $\begin{array}{c}\text { Number of cross- } \\
\text { sections }\end{array}$ & 17 & 17 \\
\hline $\begin{array}{l}\text { Number of } \\
\text { Observations }\end{array}$ & 459 & 442 \\
\hline
\end{tabular}

(Source: authors' estimates)
$(()=\mathrm{T}$ statistics; $* * *=$ significant at $1 \%, * *=$ significant at $5 \%, *=$ significant at $10 \%)$

(Coefficients robust to heteroskedasticity)

\subsection{Estimates of FEER for Brasil, India and China}

In China the beginning of the 1980s is difficult to interpret due to the mode of regulation of the external trade that prevailed at that time. However, the yuan seemed to be overvalued in the middle of the 1980s with a massive current account deficit. The introduction of an exchange rate determined in the swap centers led to a de facto devaluation that permitted to reverse this situation and yuan was even strongly undervalued in 1991 with a significant current surplus in a context of an economic slowdown. 
Figure 4: Actual and equilibrium real effective (left column) and bilateral (right column) exchange rates of the Chinese yuan, the Indian rupee and the Brazilian real $(2000=100)$
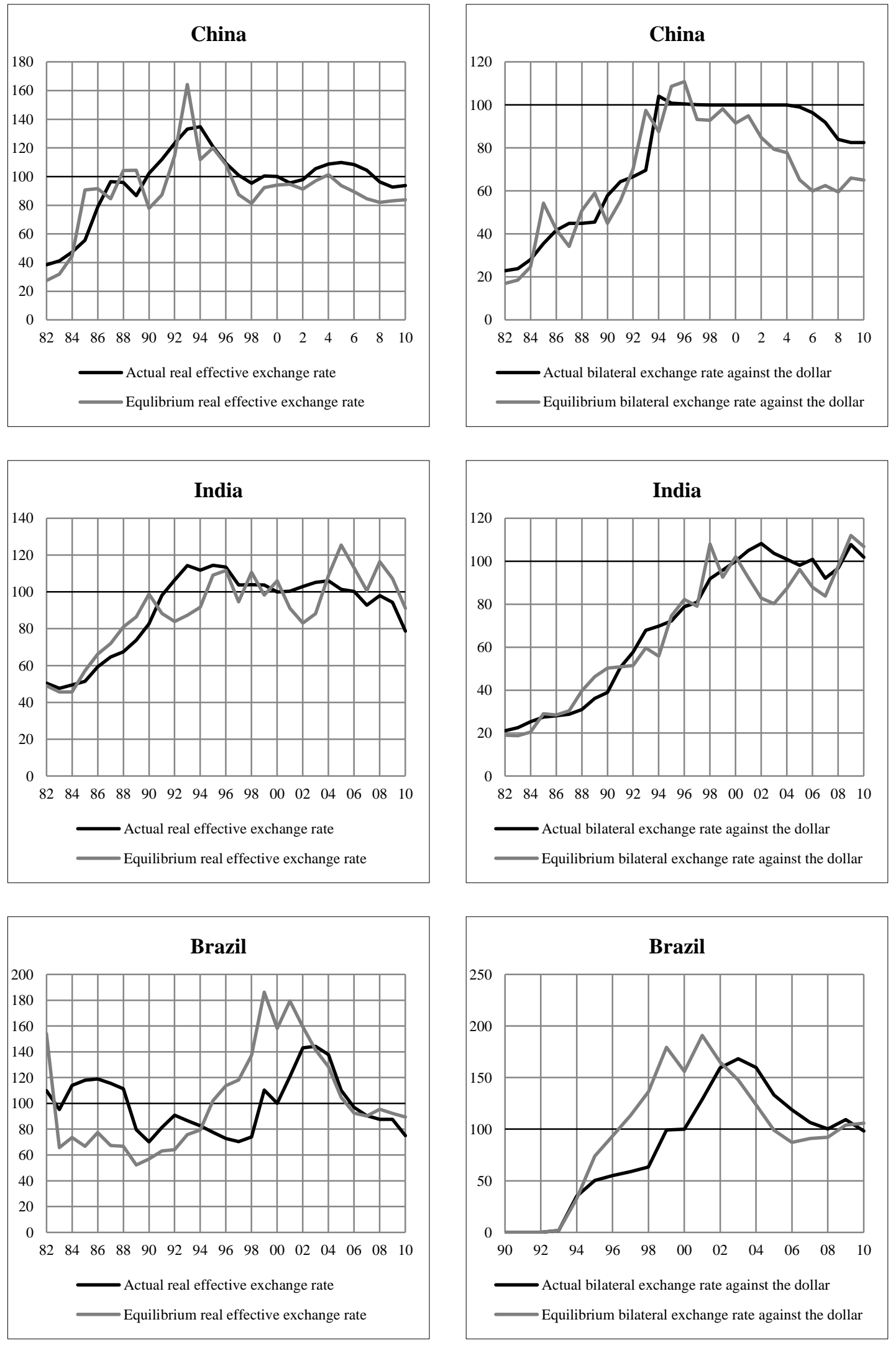

(Source: authors' calculations, IFS for bilateral exchange rates, partial data for 2010) 
Continued devaluations and the increasing usage of the swap centers exchange rate allowed the actual exchange rate to keep up with the depreciation of the equilibrium exchange rate and to preserve undervaluation during most of the time in a context of degradation of the current account and of high inflation, so that in 1994, the year of the unification of the exchange rate system, the yuan was even undervalued in nominal and real terms. The second half of the 1990s, in particular since 1997, marked a turning point. The economic boom and the return of current surplus illustrated the success of the trade openness policy of the past years. This explained the revaluation of the equilibrium exchange rate of the yuan during the second half of the 1990s, both in nominal and real terms, in sharp contrast with the previous period. The stabilization of the yuan against the dollar and even the appreciation of the real effective exchange rate of the yuan meant in fact a persistent undervaluation larger than before, both in nominal and real terms. This diagnostic could help to find an explanation of the resistance of the yuan facing the Asian crisis of 1997-1998 during which the yuan was already undervalued. However this undervaluation has been temporally reduced after the Asian crisis and the large devaluations of most of the East Asian competitors. After 2002 the undervaluation of the yuan has been amplified against the dollar, up to $47 \%$ in 2006 . It has been reduced since then, but remained high in 2009 (around 22\%). Although more moderate at the beginning of the 2000s, the undervaluation in real effective terms has increased in the second half of the 2000s (figure 4).

The evolution of the Indian rupee's exchange rate presents some similarities with the yuan case: sharp devaluation until 1994 in real effective terms and until 2002 in bilateral terms against the dollar, then stabilization in nominal terms with appreciation in real effective terms. But, beyond these rather similar evolutions, the Indian exchange rate policy appears very different. During the devaluation period, undervaluation and overvaluation have alternated as in China, but with a tendency towards a more marked and durable overvaluation. Current account deficit has been permanent and larger in India than in China, with levels frequently under the equilibrium value. After the stabilization of the real exchange rate (1994) and of the bilateral one against the dollar (2002), the overvaluation in nominal and real terms has been the rule, except during the years 2001-2003. The opposition between Chinese and Indian exchange rate policies is striking since 2004 , which has a strong impact on the growth model of the two countries.

Brazil has faced quite different issues. It began the period with an overvaluation inherited from the development scheme of the 1970s. After the contagion process of the Mexican crisis of 1982 a succession of exchange rate adjustments occurred in the framework of orthodox programs negotiated with the IMF or heterodox packages adopted in spite of Washington institutions' hostility. Combining crawling peg and, when necessary, maxi-devaluations, Brazil maintained a large undervaluation, contributing to a current account close to $0 \%$ of GDP, far above the equilibrium value, while inflation was speeding up to hyperinflation. The monetarist Collor Plan stopped this dynamic in March 1990 but, six months after, inflation resumed its race, leading to new transitory stabilization packages, including exchange rate adjustments. Consequently, until the adoption of the Real Plan in 1994, real and nominal exchange rates continued to be undervalued.

With the adoption of the Real Plan, Brazil focused on price stabilization and gave up its priority for competitiveness, stressing on capital flows to balance current deficit. In spite of the success of the Plan and some adjustments of a target zone pegged on dollar, inertial inflation entailed increasing overvaluation in real and nominal terms (-76\% against the dollar in 1998). Such imbalances could not last. At the end of 1998 contagion of the Asian and Russian crises carried on a speculative attack against a Brazilian economy mined by macroeconomic imbalances. After a 50\% devaluation and some adjustments allowed by the adoption of a floating regime, the real and nominal exchange rates returned progressively to a level close to the equilibrium one at the beginning of the 2000s, while current account became equilibrated. 
From 2002 to 2007 the real remained close to its equilibrium value in real terms and undervalued against the dollar, in spite of an appreciation trend. Current account surpluses were obtained thanks to rising raw materials' prices, dynamic world demand and improvement in competitiveness (Salama, 2009). This favorable trend was reflected in an appreciation of the equilibrium value of the real, in accordance with the observed appreciation.

With the world crisis, real appreciation and peg to the dollar became more difficult to sustain. Real overvaluation and current deficit reappeared, although limited by comparison with what has been observed in the past. However, at the end of the 2000s, Brazil, like India, is much more constrained by its exchange rate policy, in clear cut with China which uses undervaluation of the yuan at the expense of its competitors.

\subsection{Estimates of FEER for the East Asian currencies}

In Korea, a period of undervaluation of the won during the 1980s, linked to the export growth strategy, was followed by a rather marked overvaluation, both in nominal and real terms. But, at the opposite of the Japanese case, this occurred after a real depreciation during the first half of the 1980s and, then, a stable dollar-won parity. This overvaluation of the won has been regarded as one of the factors explaining the Korean crisis in 1997. The sharp devaluation of 1998 led to a large undervaluation and current surpluses. However this didn't last, as the won appreciated, both against the dollar and in real effective terms, especially against the other East Asian currencies. The current account remained in slight surplus, but generally under its equilibrium value during most of the 2000s, with a won overvalued in real terms. The undervaluation against the dollar was less pronounced than in Japan and the euro area. After the burst of the crisis in 2008 the evolution has been at the opposite of the Japanese case, with a sharp depreciation, both against the dollar and in real terms, which has allowed preserving a nominal undervaluation (figure 5).

Figure 5: Actual and equilibrium real effective and bilateral exchange rates of the won $(2000=$ 100)
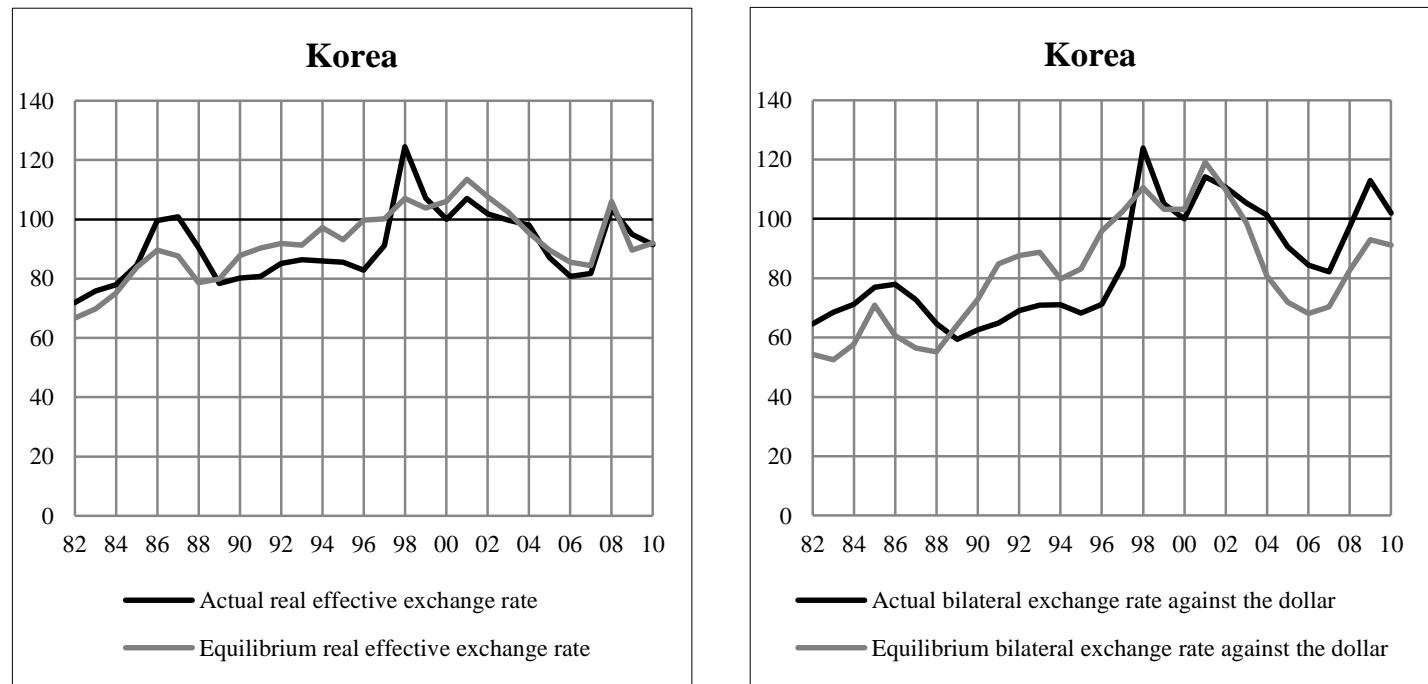

(Source: authors' calculations, IFS for bilateral exchange rates, partial data for 2010)

Thailand, Philippines and Malaysia present some similarities with respect to exchange rate policy during the 1980s. The early 1980s were marked by the end of economic boom with current account deficit and overvaluation. The peg to the dollar in the middle of the 1980s allowed a real depreciation and an improvement of their current account, leading to an undervaluation of their currencies between 1985 and 1988, especially in Philippines and to a 
less extent in Malaysia where the ringgit was close to its equilibrium value. A reversal took place at the end of the 1980s where economic recovery was related to the reappearance of important current deficits. The peg to the dollar led to large overvaluation in nominal terms, but less in real effective terms. Thailand was the most affected while the phenomenon was less marked in Philippines where the growth was more modest and current deficit more contained. The Malaysian ringgit remained as before close to equilibrium, as Malaysian economy was more trade open, which reduced misalignments' amplitude (figure 6).

Figure 6: Actual and equilibrium real effective and bilateral exchange rates of the bath, the ringgit, the Philippine peso and the Indonesian rupee $(2000=100)$
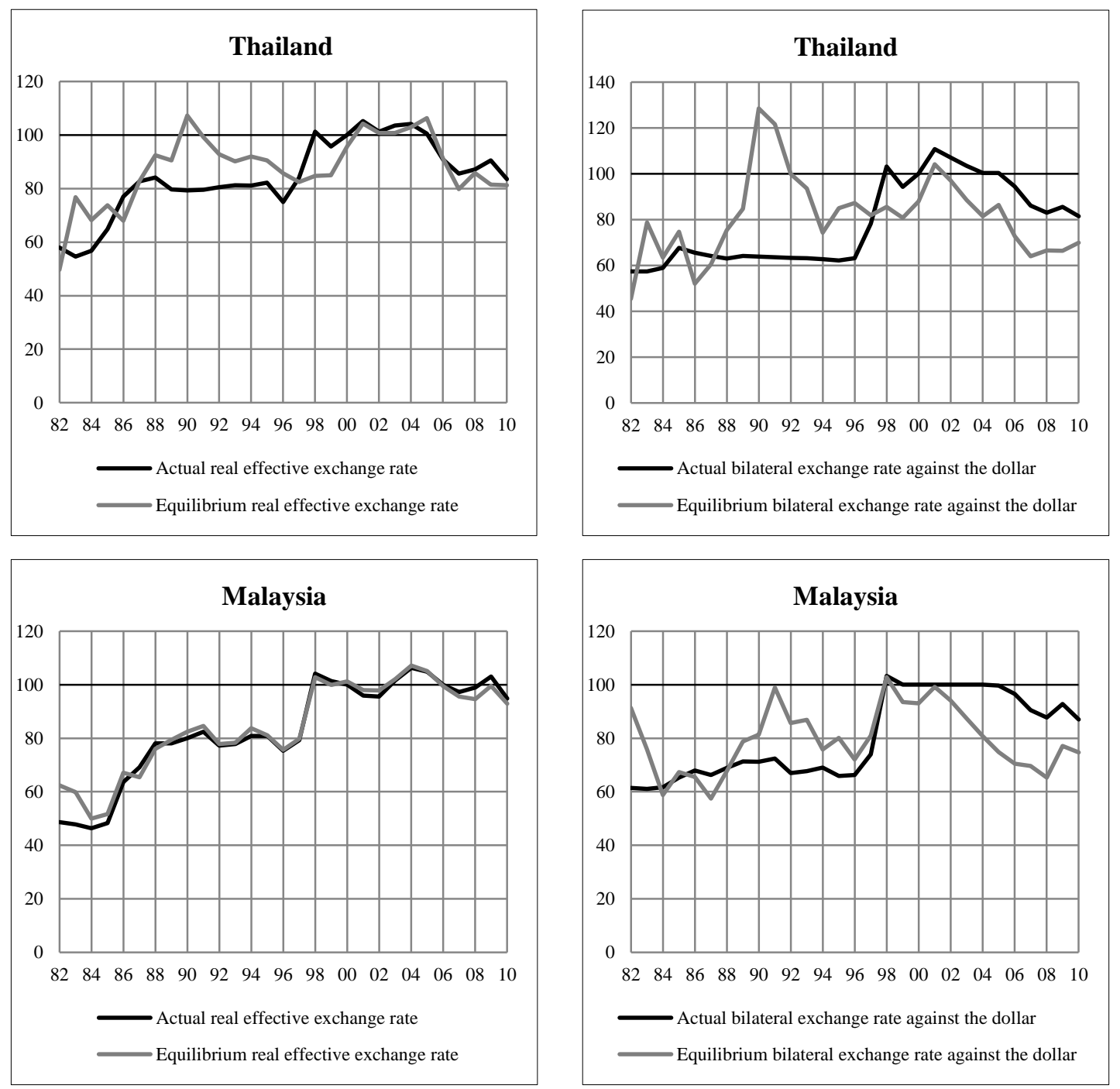

In 1996, at the eve of the Asian crisis, with newly increasing current deficit in Thailand, the bath was overvalued (-13\% in real terms, $-28 \%$ against the dollar). The overvaluation was more limited in Philippines and even less marked in Malaysia. Except for Thailand where overvaluation appeared significant (although more modest than at the start of the 1990s), overvaluation does not seem to have been the main cause of the crisis in these East Asian countries. The large devaluations following the crisis contributed to the reconstitution of important current surpluses in Thailand and Malaysia, but not durably in Philippines. The bath and, to a less extent, the ringgit became undervalued, but not the Philippine peso as Philippines faced more structural problems at that time. 
During the 2000s, in spite a general movement of appreciation, the East Asian currencies remained undervalued against the dollar (around 20-30\%), but less in real effective terms. However, compared with the Chinese yuan, they appeared far less undervalued, which induced a bias in the international competition among East Asian countries. Since the beginning of the crisis in 2007 the undervaluation has been preserved and even increased in real terms, thanks to the peg to the dollar.
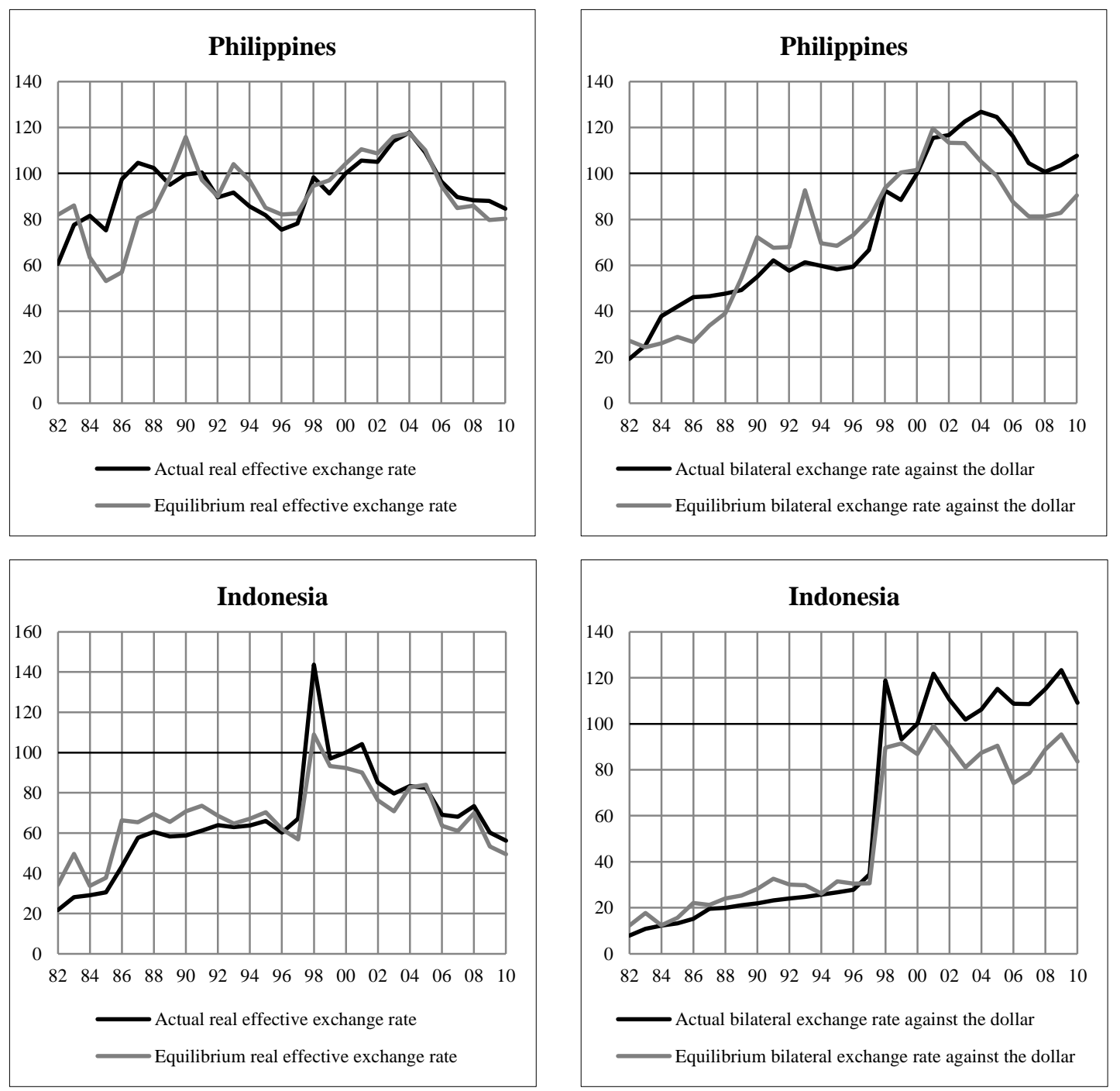

(Source: authors' calculations, IFS for bilateral exchange rates, partial data for 2010)

Indonesia, as an oil-exporting country, presents some specificity. The counter-oil shock in 1986 has degraded its current account, leading to overvaluation of its currency until the middle of the 1990s. At that time, with sustained growth and current account more under control, overvaluation became weak and did not seem to have played a large role in the crisis of 1997. However the currency the most affected by the crisis has been the Indonesian rupee, which might be explained more by political reasons and other economic imbalances than strictly monetary reasons. The devaluation of the Indonesian rupee was of the most important amplitude among the East Asian countries, in real and nominal terms. It resulted in a rather limited amelioration of the current account and in an undervaluation of the rupee which could be regarded as modest, compared with the amplitude of the shock. This result could reflect the 
destructive effects of the crisis on the Indonesian productive system. The situation has been progressively normalized afterwards, the country taking advantage of the rising oil prices during the 2000s. The undervaluation of the Indonesian rupee (around 20-30\% against the dollar) was in line with the other East Asian countries at the end of the 2000s, but slightly less pronounced in real terms.

\subsection{Estimates of FEER for other Latin American currencies}

Contrary to the East Asian countries, ERM of the Latin American countries are wider and more dispersed, due to larger heterogeneity and smaller economic integration between countries. If they are all affected by the debt crisis of the 1980s, the financial recovery following the Brady Plan in the late 1980s, the speculative crises of the end of the 1990s and the last financial crisis, varieties of stabilization and nominal exchange rate policies determine very different macroeconomic paths and imbalances. Argentine and Mexican cases are interesting to examine first in this perspective.

In Argentina, at the beginning of the 1980s, accelerating inflation entailed the overvaluation of the peso and large current deficits in spite of the crawling peg regime. After a new stabilization package the government adopted the heterodox Austral plan in 1985 aimed to break inflation by a policy mix combining prices, wages and exchange rates freezing after a sharp devaluation. After a while, the loosening of this policy brought about a return of inflation and overvaluation, as the government delayed exchange rate adjustments to fight inflation.

A succession of stabilization plans were then implemented with more accommodating exchange rate policy aimed to preserve competitiveness, which led to undervaluation of the peso and current surplus in 1988 and 1989. But accelerating inflation led the Menem government to experiment various packages before the adoption of a more radical program based on a currency board in 1991. This led to a sharp real appreciation, huge current deficit and large overvaluation between 1992 and the burst of the crisis in 2001. The end of the currency board and the maxidevaluation induced a strong reversal with durable undervaluation in nominal terms against the dollar (around 30\%) during the 2000s and, to a less extent, in real effective terms (from $40 \%$ down to $5 \%$ and up to around $15 \%$ ) with large current surplus in a favorable context of rising oil and commodities prices. Consequently, Argentina faced the last crisis in a better position with an undervalued peso and rising current surplus in spite of a moderate appreciation in real and nominal terms. However the real undervaluation may be overestimated in the last years, as the official statistics of prices used to evaluate real exchange rates are known as underestimating the actual rate of inflation (figure 7).

Although large, the amplitude of exchange rate's evolutions is more limited in Mexico than in Argentina. The debt crisis originated in Mexico in 1982 led to an inflationary cycle with price explosion and strong exchange rate depreciation. Successive failure of stabilization plans entailed a dramatic chase between price hikes and exchange rate adjustments allowing however a steady undervaluation, both in nominal and real terms with current surplus far above the equilibrium value.

The heterodox Pact for economic solidarity of December 1987 combined fiscal adjustment, a fixed exchange rate (followed by some slight depreciations), a temporary freeze of wages and 
prices and strong trade liberalization. The program succeeded in stopping inflation, but residual inflation entailed a strong real appreciation and growing current deficits (-6\% of GDP between 1992 and 1994), favored by trade liberalization. An increasing overvaluation appeared, both in nominal and real terms.

Figure 7: Actual and equilibrium real effective and bilateral exchange rates of the Argentine and the Mexican pesos $(2000=100)$
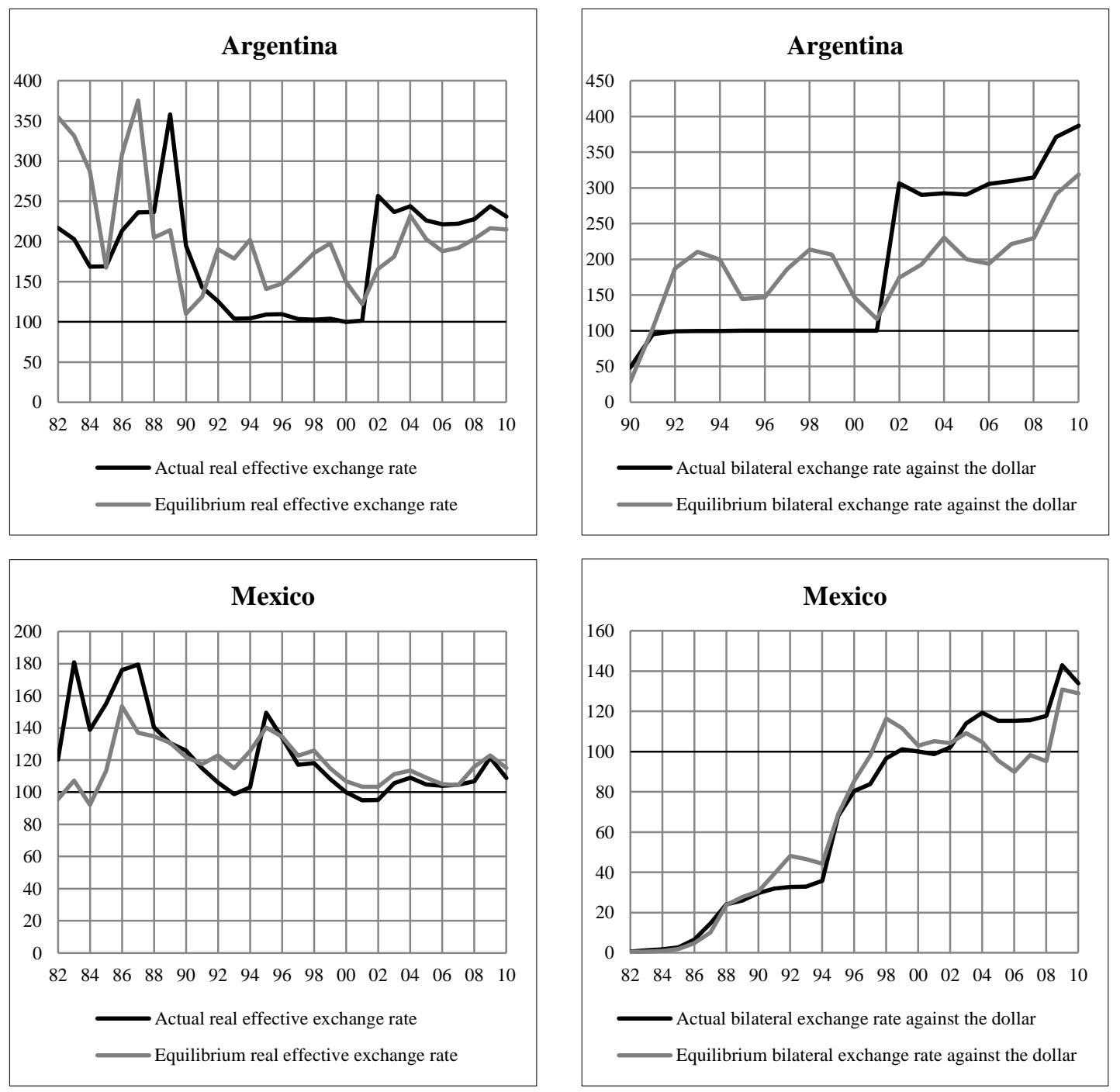

(Source: authors' calculations, IFS for bilateral exchange rates, partial data for 2010)

Until 1992 external imbalances were regarded as sustainable, thanks to capital flows, following the Brady plan of 1989, and privatizations. But, in spite of important FDI, a large part of these capital flows were portfolio investment flows more reversible. Successive speculative attacks (the Tequila crisis in 1995) led to the abandon of the target zone exchange rate regime for floating with a large devaluation nominal and real and a dramatic slump. The current balance improved strongly and exchange rate became close to its equilibrium value. The large financial mobilization of IMF and the USA during the collapse and a successful stabilization package helped Mexican economy to recover external credibility and growth. But Mexico was touched indirectly by the Asian and Russian crises in 1997-1998 which led the government to devaluate by steps. In spite of this, the peso appreciated in real terms and became slightly overvalued in real terms and against the dollar until 2002. 
After a new depreciation against the dollar, the peso remained stable in real terms and close to equilibrium, with a progressive improvement of the current account. In 2008 the world crisis and the drop of the trade with the USA led to a new decline of the current account and a limited overvaluation. The Mexican economy seems in a more balanced situation to face the present crisis than in previous periods but its exchange rate policy is more constrained than in other emerging countries.

Figure 8: Actual and equilibrium real effective and bilateral exchange rates for Chile and Colombia $(2000=\mathbf{1 0 0})$
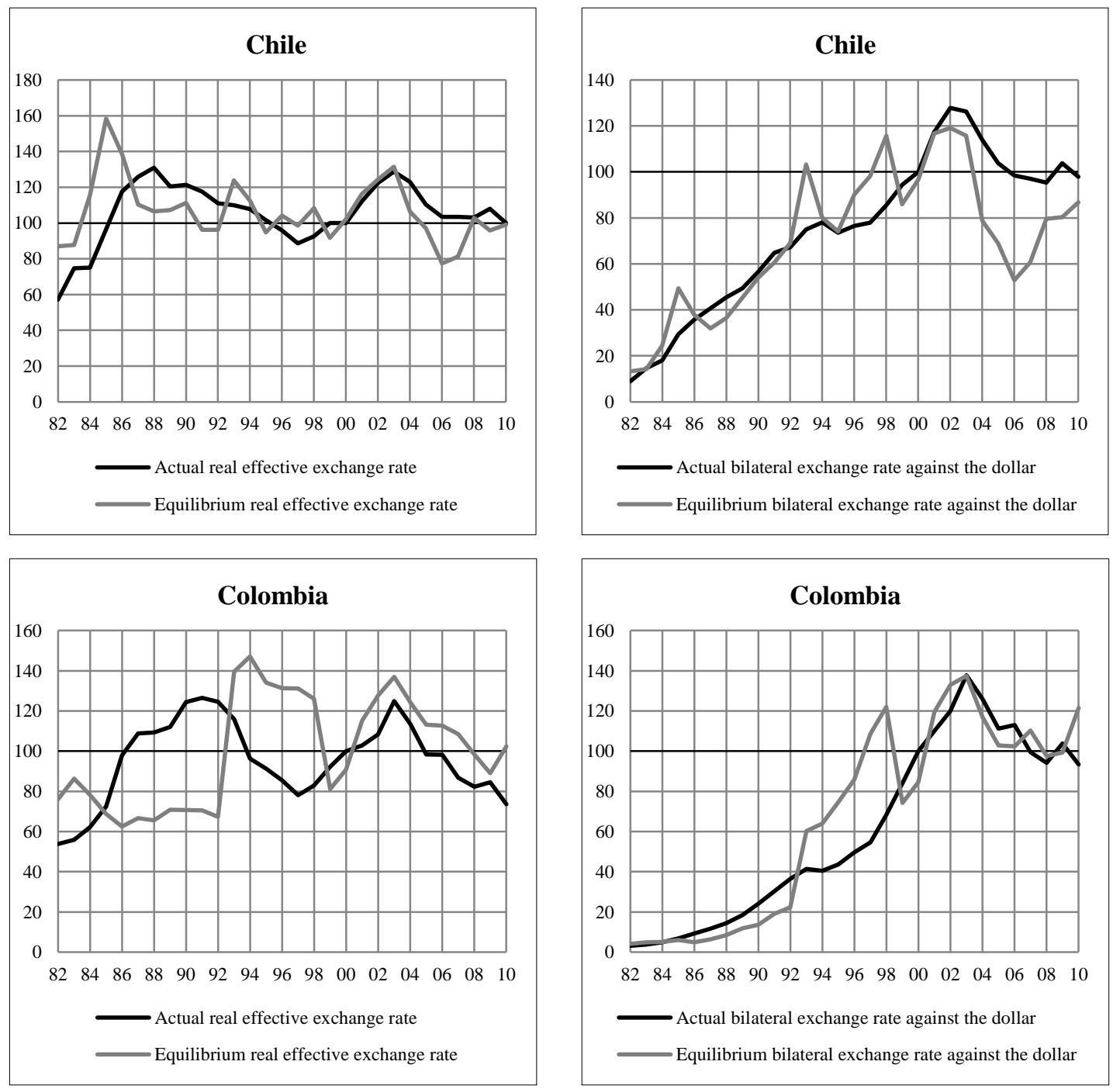

(Source: authors' calculations, IFS for bilateral exchange rates, partial data for 2010)

Chile inherited of an imbalanced situation at the beginning of the 1980s with inflation and growing current deficit (-15\% of GDP in 1981). In spite of a sharp devaluation in 1981 the inversion of the capital inflows led to the adoption of floating exchange rate. Large nominal and real depreciations followed, but important overvaluation remained until 1987 with progressively improving current account. From the end of the 1980s to the end of the 1990s a more balanced situation prevailed with stabilized nominal exchange rate, moderate real appreciation, limited current deficit and a currency often undervalued in real terms. The Asian and Russian crises were destabilizing factors with new imbalances and overvaluations. However nominal and real depreciations up to 2003 helped to recover equilibrium exchange 
rates and to improve current account. Since then, the Chilean economy enjoyed a rather steady and sustainable growth with growing current surplus (5\% of GDP in 2006-2007), a currency appreciating in nominal and real terms while keeping large undervaluation. Although negatively affected by the world crisis of 2008 , Chile faced it in a rather balanced position in spite of its reduced room for manoeuvre (figure 8).

Colombia presents some similarity with Chile in terms of exchange rate profile, a long nominal depreciation up to 2002, a real depreciation during the 1980s followed by a more stabilized evolution with alternative periods of appreciation and depreciation. But imbalances have been far more important with current deficits and overvaluation at the beginning of 1980s, a long period of huge surpluses (4\% of GDP in 1991) and massive undervaluation (around 40-60\% in nominal and real terms) up to 1992. Since then, current deficits and large overvaluation have been the rule, except a brief improvement in 1999-2000. The Columbian economy faced the world crisis of 2008 in a more fragile and unbalanced position.

\section{Conclusion}

Some general lessons can be drawn from this estimation of ERM and current account imbalances of the emerging countries since the 1980s.

Among the BRICs, the main emerging countries, the exchange rate policy has been contrasted. The Chinese case is the most well known. From the 1980s to 1994 the trade openness strategy has been based on a depreciation of the yuan in real and nominal terms with alternatively periods of under and overvaluation, but preserving more undervaluation and avoiding the recourse to external indebtedness. Since the middle of the 1990s a turning point has appeared with a permanent yuan undervaluation in real and nominal terms, due to a real revaluation of the yuan smaller than the equilibrium exchange rate's revaluation which resulted from the success of the Chinese strategy of openness. This undervaluation has been temporally attenuated with the consequences of the Asian crisis of 1997-1998, but it has amplified since 2002 and remained after the financial crisis of 2007. Chinese surpluses are one of the symptoms of the persistent international imbalances.

India has followed a different path, although there are similarities with China in the exchange rate's evolution: long period of real and nominal depreciations, followed at the end of the 1990s by a real appreciation and a nominal stabilization. But, during the depreciation period the duration of overvaluation has been longer than in China, with current imbalances more pronounced. After the stabilization the overvaluation has been almost the rule, with persistent current deficits, except for a short period between 2001 and 2003. India didn't enjoy a revaluation of its equilibrium exchange rate as China did, which can be interpreted as a less successful policy of liberalization and trade openness. Since the burst of the crisis of 2008 the rupee's overvaluation and current imbalances have amplified, which is rather scarce among emerging countries. It means huge overvaluation against the other Asian partners and put constraints on the future potential growth of India.

Brazil is a last case where three different periods can be distinguished. From the beginning of the 1980s to the adoption of the Real plan in 1994, a succession of stabilization programs and exchange rate adjustments tried to preserve competitiveness through permanent real and nominal undervaluation, but with great difficulties in controlling inflation. From 1994 to 2002 more focus was put on inflation stabilization and less on competitiveness, as foreign capital flows financed current deficits. Real and nominal overvaluation was permanent, but gradually decreased after 1998 and the return of devaluations. Since 2002 a more balanced situation 
prevailed with no misalignments in real terms, an undervaluation against the dollar and an appreciation of the equilibrium exchange rate which reflected improvement in Brazilian competitiveness. But the economic environment deteriorates with the burst of the crisis. Undervaluation against the dollar have disappeared and real overvaluation is back, although moderately.

East Asian countries, including Korea, have roughly followed the same path in spite of inequality in the level of development: real and, often, nominal depreciation until the end of the 1980s, stabilization against the dollar with, in some cases, real appreciation during the 1990s, large devaluations after the Asian crisis of 1997-1998 followed, more or less rapidly, by revaluation against the dollar and in real terms. There is no general configuration in terms of under or overvaluation for all the East Asian currencies during the 1980s and 1990s. Periods of undervaluation and overvaluation have alternatively prevailed. Indonesia occupied a specific position due to its status of oil producer. The Korean won and Thai baht were more overvalued before the Asian crisis of 1997. After the huge devaluations of 1997-1998 the real undervaluation didn't last and misalignments remained limited in real terms, but not against the dollar. During the 2000s all the East Asian currencies were undervalued against the dollar, but less than the yuan and the yen and more than the euro after its revaluation in the second half of the 2000s. Since the burst of the financial crisis of 2008, the undervaluation has been preserved against the dollar and amplified in real terms with rising current surpluses, above their equilibrium values. This configuration, although less marked than in the Chinese case, contributes to the persistence of current imbalances.

Latin American countries have known wider and more dispersed misalignments and current imbalances, but nominal stabilization has been observed since the 2000s. Argentina experimented three contrasted periods. During the 1980s a succession of stabilization plans trying to fight inflation led to overvaluation and was followed by policies more turned towards competitiveness, inducing undervaluation, but also high inflation. During the 1990s the currency board regime led to huge deficits and overvaluation until the crisis of 2001 . After the maxi-devaluation, undervaluation against the dollar prevailed, but was less durable in real terms. However Argentina faced the world crisis of 2008 in a more comfortable position with large surpluses and undervaluation, although the question of the measure of inflation induces some uncertainty.

In Mexico three periods can also be considered. The first part of the 1980s was marked by stabilization plans which failed, but preserved undervaluation and current surpluses. From 1987 to the crisis of 1995 more heterodox plans, followed by trade liberalization, succeeded in stopping inflation, but entailed large overvaluation and current deficits. Since then, successive devaluations limited the overvaluation and the imbalances' amplitude and led to a progressive stabilization. In spite of this, facing the crisis of 2008, the room for manoeuvre of the Mexican economy, closely connected with the US, seems relatively limited.

Chile and Colombia present some similarities in their exchange rate evolution, a long nominal depreciation up to 2002 and a succession of depreciation and appreciation in real terms. In Chile, after an overvaluation period during the first part of 1980s, a more balanced situation prevailed in spite of the destabilizing effects of the Asian crisis of 1997 and of the financial crisis of 2008. On long period imbalances have been much larger in Colombia and overvaluation has tended to amplify during the last crisis. On the contrary Uruguay has reduced its overvaluation since the middle of the 2000s. 
On the whole in 2010, the dollar was still overvalued against all the East Asian currencies, except the yen which was close to equilibrium. The undervaluation of the yuan was the largest one. The dollar was also overvalued against some Latin American economies (Argentina, Chile and Uruguay) which benefited of undervalued currencies in real terms. Brazil and Mexico had currencies close to equilibrium against the dollar, but were slightly overvalued in real terms, which reduced their room for manoeuvre, especially for Mexico. The euro area, as a whole, was also close to equilibrium, but faced mainly huge intra-European imbalances. Last, Colombia and, above all, India suffered of overvalued currencies against the dollar and in real terms. 


\section{Appendix 1: National model in differential logarithmic}

National model in logarithmic differentials $\left(x=d \log X=d X / X=\left(X-X^{e}\right) / X^{e}\right)$ is transformed into:

$$
\begin{gathered}
x_{i}=\eta x_{i} d_{i}^{*}+\left(1-\alpha x_{i}\right) \varepsilon x_{i} r_{i} \\
m_{i}=\eta m_{i} d i_{i}-\left(\alpha m_{i} \varepsilon m_{i}\right) r_{i} \\
p x_{i}=\alpha x_{i} r_{i}+p_{i} \\
p m_{i}=\alpha m_{i} r_{i}+p_{i} \\
b_{i}=\mu_{i} T_{i}\left(1-\sigma_{p e t x i}-\sigma_{x i}\right)\left(p x_{i}+x_{i}-p m_{i}-m_{i}\right)
\end{gathered}
$$

The national model variables are defined as follow: $X$, non-oil exports in volume; $D^{*}$, world demand in volume; $P^{*}$, world prices; $P X$, export prices; $M$, non-oil imports in volume; $D I$, internal demand in volume; $P M$, import prices; $P$, production prices; $E$, bilateral exchange rate against the dollar; $R$, real effective exchange rates; $B$, current balance; $i$, interest rates for external debt; $F$, net external debt; $P_{p e t}$, oil price; $M_{p e t}$, net oil import; $T$, ratio of nominal export on nominal import; $\mu$, ratio of nominal import on nominal GDP, $\sigma_{p e t x}=E P_{p e t} M_{p e t} / P X X$ is the ratio of net oil imports on non-oil exports and $\sigma_{x}=i E F / P X X$ is the ratio of foreign debt service on non-oil exports.

$b$ is the difference between the observed current account and the equilibrium one, as percentage of GDP.The way the equation [9] is derived can be explained:

$$
\begin{gathered}
b_{i}=\left(\frac{B_{i}}{P_{i} Y_{i}}\right)-\left(\frac{B_{i}^{e}}{P_{i}^{e} Y_{i}^{e}}\right)=d\left(\frac{B_{i}}{P_{i} Y_{i}}\right)=\mu_{i} d\left(\frac{B_{i}}{P M_{i} M_{i}}\right) \\
b_{i}=\mu_{i} d\left[\left(\frac{P X_{i} X_{i}}{P M_{i} M_{i}}\right)-1-\left(\frac{E P_{p e t} M_{p e t i}}{P X_{i} X_{i}}\right)\left(\frac{P X_{i} X_{i}}{P M_{i} M_{i}}\right)-\left(\frac{i_{i} E_{i} F_{i}}{P X_{i} X_{i}}\right)\left(\frac{P X_{i} X_{i}}{P M_{i} M_{i}}\right)\right] \\
b_{i}=\mu_{i} d T_{i}\left(1-\sigma_{p e t x i}-\sigma_{x i}\right)
\end{gathered}
$$

We can compute $r$ (equation [1]), the misalignment of "national euro" in real effective terms ( $r$ $\left.=d \log R=d R / R=\left(R-R^{e}\right) / R^{e}\right)$ :

$$
\begin{gathered}
\frac{d T_{i}}{T_{i}}=p x_{i}+x_{i}-p m_{i}-m_{i} \\
\frac{d T_{i}}{T_{i}}=\left(\eta x_{i} d_{i}^{*}-\eta m_{i} d i_{i}\right)+\left[\left(1-\alpha x_{i} \varepsilon x_{i}\right)+\varepsilon m_{i} \alpha m_{i}+\alpha x_{i}-\alpha m_{i}\right] r_{i} \\
b_{i}=\mu_{i} d T_{i}\left(1-\sigma_{p e t x i}-\sigma_{x i}\right)
\end{gathered}
$$




$$
\begin{gathered}
\frac{d T_{i}}{T_{i}}=\frac{b_{i}}{\mu_{i} T_{i}\left(1-\sigma_{p e t x i}-\sigma_{x i}\right)} \\
r_{i}=\left[\frac{\left(\left(b_{i} /\left[\mu_{i} T_{i}\left(1-\sigma_{p e t x i}-\sigma_{x i}\right)\right]\right)+\eta m_{i} d i_{i}-\eta x_{i} d_{i}^{*}\right)}{\left(\left(1-\alpha x_{i}\right) \varepsilon x_{i}+\varepsilon m_{i} \alpha m_{i}+\alpha x_{i}-\alpha m_{i}\right)}\right]
\end{gathered}
$$

By using the equation of the real effective exchange rate, we can find out $e$, the degree of misalignment in bilateral nominal terms (equation [2]); the partner countries' misalignments are given by the previous multinational model:

$$
r_{i}=e_{i}+p x_{i}^{*}-p_{i}
$$

Like in the multinational model, we suppose that $p_{i}=\frac{\left(P_{i}-P_{i}^{e}\right)}{P_{i}^{e}}=0$

$$
e_{i}=r_{i}-\sum_{j \neq i} \lambda_{i j}\left(p x_{j}-e_{j}\right)
$$

We can also compute the effective ERM based on consumer prices (PD) (equation [3]):

$$
\begin{gathered}
R C_{i}=\frac{E_{i} P D_{i}^{*}}{P D_{i}} \\
r c_{i}=e_{i}+p d_{i}^{*}-p d_{i} \\
p d_{i}^{*}=\sum_{j \neq i} v_{i j}\left(p d_{j}-e_{j}\right) \\
p d_{i}=\mu_{i} p m_{i}+\left(1-\mu_{i}\right) p_{i} \\
p m_{i}=\alpha m_{i}\left(e_{i}+p m_{i}^{*}\right)+\left(1-\alpha m_{i}\right) p_{i} \\
p d_{i}=\alpha m_{i} \mu_{i}\left(e_{i}+p m_{i}^{*}\right) \\
r c_{i}=\left(1-\alpha m_{i} \mu_{i}\right) r_{i}+p d_{i}^{*}-p x_{i}^{*} \\
r c_{i}=\left(1-\alpha m_{i} \mu_{i}\right) r_{i}+\sum_{j \neq i} v_{i j}\left(p d_{j}-e_{j}\right)-\sum_{j \neq i} \lambda_{i j}\left(p x_{j}-e_{j}\right)
\end{gathered}
$$

$\left(p d_{j}, e_{j}, p x_{j}\right.$ obtained thanks to the multinational model) 


\section{Appendix 2: Trade elasticities}

The elasticities of the MIMOSA model for Japan, the United States and the United Kingdom (close to those of Wren-Lewis), those of Dées (1999) for China and those of Hervé (2000) for the Euro area are taken for our simulation. The price elasticities are rather in accordance with the generally admitted hierarchical position of countries in the world trade. The relatively weak value for China could be surprising, but might be explained by the particular nature of the Chinese trade. The trade model of China was estimated for the period 1985-1998 and for the first half of the 1980s the role of exchange rates in exports and imports is considered as little significant. Notice also that Japanese and American exporters turn out to be largely price maker. The price elasticities are weaker in the OECD (2005) publication as they concern the total trade of goods and services. For the Rest of the World, estimation of elasticities has been made using data from CHELEM and OECD.

For emerging countries, studies of Senhadji (1998), Senhadji \& Montenegro (1999), Barrel et al., (1999), Ito et al. (1996) and of IMF (2000) have been used. For Korea and Thailand Barell's results, close to those of Senhadji, have been taken whereas for Indonesia FMI's elasticities have appeared more significant. For India Senhadji's results have been used. Two problems appeared for Malaysia and Philippines. Import price elasticity of Malaysia estimated by IMF seemed too weak while Philippines' one estimated by Senhadji was very high, especially compared with IMF results. For these two countries, mean values obtained for the whole set of Senhadji's emerging countries have been preferred for import price and income elasticities ( $\mathrm{\varepsilon m}$ $=1.4 ; \eta \mathrm{m}=1.1)$. Last, for Uruguay also, the import income elasticity appeared too high and a smaller value (1.5) has been used.

\begin{tabular}{cccccc}
\hline Country & Source & $\varepsilon_{x}$ & $\varepsilon_{m}$ & $\eta_{x}$ & $\eta_{m}$ \\
\hline \multirow{2}{*}{ Korea } & Barell & $\mathbf{2 . 2 0}$ & $\mathbf{1 . 2 0}$ & $\mathbf{2 . 0 0}$ & $\mathbf{1 . 2 0}$ \\
& Kim & 1.11 & 0.10 & 1.29 & 1.59 \\
\hline India & Senhadji & $\mathbf{0 . 7 7}$ & $\mathbf{1 . 1 2}$ & $\mathbf{1 . 5 5}$ & $\mathbf{1 . 3 3}$ \\
\hline \multirow{2}{*}{ Indonesia } & IMF & $\mathbf{0 . 3 2}$ & $\mathbf{0 . 6 8}$ & $\mathbf{1 . 2 7}$ & $\mathbf{1 . 6 6}$ \\
\hline Malaysia & Senhadji & - & 1.51 & - & 0.98 \\
\hline \multirow{2}{*}{ Philippines } & IMF & $\mathbf{0 . 5 3}$ & 0.01 & $\mathbf{1 . 8 6}$ & 1.47 \\
& IMF & -0.10 & -0.75 & 1.34 & 1.65 \\
& Senhadji & $\mathbf{1 . 2 2}$ & 2.73 & $\mathbf{1 . 1 9}$ & 2.26 \\
\hline \multirow{2}{*}{ Thailand } & IMF & 0.99 & 0.75 & 2.73 & 1.03 \\
& Barell & $\mathbf{0 . 4 5}$ & $\mathbf{0 . 9 3}$ & $\mathbf{2 . 5 9}$ & $\mathbf{1 . 5 9}$ \\
\hline Argentina & Senhadji & - & 1.37 & - & 1.69 \\
\hline Brazil & Senhadji & $\mathbf{0 . 2 4}$ & $\mathbf{1 . 0 7}$ & $\mathbf{1 . 2 8}$ & $\mathbf{1 . 2 7}$ \\
\hline \multirow{2}{*}{ Chile } & Senhadji & $\mathbf{1 . 6 0}$ & $\mathbf{1 . 8 1}$ & $\mathbf{2 . 1 0}$ & $\mathbf{1 . 2 5}$ \\
\hline Colombia & Ito et al. & 0.10 & 0.23 & 2.87 & 1.70 \\
\hline \multirow{2}{*}{ Mexico } & Senhadji & $\mathbf{0 . 1 0}$ & 0.02 & $\mathbf{2 . 8 7}$ & $\mathbf{1 . 7 0}$ \\
\hline Sruguay & Senhadji & $\mathbf{1 . 7 3}$ & $\mathbf{0 . 7 8}$ & $\mathbf{1 . 3 9}$ & $\mathbf{1 . 0 9}$ \\
\hline & Sto enadji & - & 0.79 & - & 1.32 \\
& Senhadji & $\mathbf{0 . 7 7}$ & $\mathbf{1 . 4 3}$ & $\mathbf{1 . 5 5}$ & $\mathbf{1 . 6 0}$ \\
\hline
\end{tabular}




\section{Appendix 3: Sensitivity tests}

Considering the existing uncertainties in the estimation of external and internal equilibrium and in the measure of trade elasticities, three kinds of sensibility tests have been performed:

- $\quad$ an increase of the target current balance of 1\% of GDP $(b c)$;

- an increase of the potential production of $1 \%\left(y^{e}\right)$;

- an increase of the export price elasticity of $20 \%\left(\varepsilon_{x}\right)$;

- an increase of the import price elasticity of $20 \%\left(\varepsilon_{m}\right)$.

Table 4: Sensitivity tests on real effective exchange rates ( $\mathrm{rc}$ )

\begin{tabular}{ccccc}
\hline & $b c$ & $y^{e}$ & $\varepsilon_{x}$ & $\varepsilon_{m}$ \\
\hline Korea & 0.0066 & 0.0022 & 0.0014 & 0.0029 \\
India & 0.0542 & 0.0021 & 0.0004 & 0.0070 \\
Indonesia & 0.0140 & 0.0143 & 0.0146 & 0.0152 \\
Malaysia & 0.0030 & 0.0157 & 0.0162 & 0.0126 \\
Philippines & 0.0127 & 0.0052 & 0.0053 & 0.0063 \\
Thailand & 0.0120 & 0.0045 & 0.0043 & 0.0064 \\
Argentina & 0.0492 & 0.0169 & 0.0171 & 0.0203 \\
Brazil & 0.0365 & 0.0062 & 0.0060 & 0.0150 \\
Chile & 0.0202 & 0.0037 & 0.0001 & 0.0065 \\
Colombia & 0.0468 & 0.0100 & 0.0042 & 0.0110 \\
Mexico & 0.0113 & 0.0106 & 0.0046 & 0.0063 \\
Uruguay & 0.0209 & 0.0206 & 0.0072 & 0.0092 \\
\hline
\end{tabular}

(Source: authors' calculations, absolute average of changes from the base simulation results)

\section{Appendix 4: Sources}

\begin{tabular}{|c|c|}
\hline Variable & Source \\
\hline CAS & World Economic Outlook, IMF, April 2010 \\
\hline ISNFA & P.R. Lane and G.M. Milesi-Ferretti's Database, 2007 \\
\hline$C D R, O D R$ & World population prospect, ONU, Last update, September 28, 2007 \\
\hline$O G$ & $\begin{array}{c}\text { Economic Outlook, OECD, December } 2008 \\
\text { (for emerging countries, author's calculations) }\end{array}$ \\
\hline $\begin{array}{l}\text { OB, ACRMAN, } \\
\text { XREG, OPEN }\end{array}$ & CHELEM, CEPII's Database, 2009, 2010 \\
\hline RKAOPEN & $\begin{array}{c}\text { Chinn and Ito Index 2008, } \\
\text { World Economic Outlook, IMF, April } 2010\end{array}$ \\
\hline ERR & Annual Report on Exchange Arrangements and Exchange Restrictions, IMF \\
\hline
\end{tabular}




\section{Appendix 5: Panel unit root test}

Table 5: Panel unit root test for industrialized countries

\begin{tabular}{ccc}
\hline & Level & First Difference \\
\cline { 2 - 3 } $\boldsymbol{C A}$ & $\boldsymbol{I P S}$ & $\boldsymbol{I P S}$ \\
\hline $\boldsymbol{I S N F A}$ & $-2.16^{* *}$ & $-7.87 * * *$ \\
$\boldsymbol{C D R}$ & $-1.20^{* * *}$ & $-3.81 * * *$ \\
$\boldsymbol{O D} \boldsymbol{R}$ & $-3.83^{* * *}$ & $-3.98 * * *$ \\
$\boldsymbol{O G}$ & $-11.29 * * *$ & $-8.73 * * *$ \\
\hline
\end{tabular}

(Source: authors' calculation)

$(* * *=$ Significant at $1 \%, * *=$ significant at $5 \%, *=$ significant at $10 \%$ using the test statistic Im Pesaran Shin; the rejection of the null hypothesis (of the presence of unit root), leads us to reject non-stationarity of the series.)

Table 6: Panel unit root test for emerging countries

\begin{tabular}{ccc}
\hline & Level & First Difference \\
\cline { 2 - 3 } $\boldsymbol{C A}$ & $\boldsymbol{I P S}$ & $\boldsymbol{I P S}$ \\
\hline $\boldsymbol{I S N F \boldsymbol { A }}$ & $-3.32 * * *$ & $-5.93 * * *$ \\
$\boldsymbol{D} \boldsymbol{R}$ & $-2.23 * *$ & $-4.34 * * *$ \\
$\boldsymbol{O B}$ & $-2.48^{* * *}$ & $-4.08^{* * *}$ \\
$\boldsymbol{O G}$ & $-4.08 * * *$ & $-3.62 * * *$ \\
\hline
\end{tabular}

(Source: authors' calculation)

$(* * *=$ Significant at $1 \%, * *=$ significant at $5 \%, *=$ significant at $10 \%$ using the test statistic Im Pesaran Shin; the rejection of the null hypothesis (of the presence of unit root), leads us to reject non-stationarity of the series.) 
Appendix 6: Undervaluation (e $>0$ and $r>0)$ or overvaluation $(e<0$ and $r<0)$ (in \%)

Table 7: Undervaluation $(\mathrm{e}>0$ and $\mathrm{r}>0)$ or overvaluation $(\mathrm{e}<0$ and $\mathrm{r}<0)$ for the U.S., the, Euro area, Brazil, Argentina, Mexico, Chile and Colombia (in \%)

\begin{tabular}{|c|c|c|c|c|c|c|c|c|c|c|c|c|c|c|c|}
\hline & \multicolumn{7}{|c|}{ Nominal Bilateral } & \multicolumn{8}{|c|}{ Real Effective } \\
\hline & $E U$ & $J P N$ & $B R A$ & $A R G$ & $M E X$ & $\mathrm{CHI}$ & $C O L$ & $U S$ & $E U$ & $J P N$ & $B R A$ & $A R G$ & $M E X$ & $\mathrm{CHI}$ & $C O L$ \\
\hline 1982 & 2.8 & -3.0 & -28.1 & -44.3 & & -39.9 & -30.2 & 13.8 & 8.0 & 4.9 & -33.8 & & 22.9 & & -34.7 \\
\hline 1983 & 14.1 & 1.2 & 60.3 & -31.0 & 75.4 & 2.5 & -27.3 & 7.4 & 15.2 & 5.2 & 37.1 & -49.2 & 52.2 & -15.9 & -43.6 \\
\hline 1984 & 18.2 & 10.3 & 66.9 & -35.2 & 63.8 & -30.6 & -4.8 & -3.9 & 12.2 & 5.5 & 57.1 & -53.3 & 40.9 & -43.3 & -23.2 \\
\hline 1985 & 27.4 & 18.9 & 66.7 & 8.2 & 41.2 & -51.5 & 12.8 & -7.4 & 19.1 & 14.1 & 43.2 & 0.9 & 31.5 & -49.5 & 5.1 \\
\hline 1986 & 33.2 & 21.0 & 59.0 & -24.7 & 29.1 & -5.5 & 62.9 & -7.8 & 21.0 & 11.0 & 43.0 & -36.8 & 13.7 & -16.6 & 44.9 \\
\hline 1987 & 21.6 & 17.3 & 64.2 & -41.2 & 37.5 & 24.0 & 61.3 & -9.3 & 11.0 & 6.9 & 54.0 & -46.3 & 27.1 & 13.3 & 48.9 \\
\hline 1988 & 5.3 & -2.0 & 50.4 & 11.8 & 1.6 & 22.3 & 53.4 & 5.3 & 9.5 & 1.9 & 51.4 & 14.3 & 4.1 & 20.6 & 51.0 \\
\hline 1989 & 5.1 & -2.7 & 37.4 & 47.8 & -6.6 & 8.7 & 44.3 & 9.6 & 11.7 & 4.1 & 42.1 & 51.4 & -0.2 & 11.7 & 45.9 \\
\hline 1990 & -3.4 & 0.2 & 15.9 & 53.2 & -2.4 & 4.5 & 57.0 & 15.1 & 1.2 & 4.3 & 21.0 & 57.4 & 3.3 & 8.6 & 56.7 \\
\hline 1991 & -22.1 & -4.9 & 9.7 & -8.5 & -20.7 & 6.6 & 46.6 & 23.6 & -10.6 & 6.1 & 25.5 & 8.3 & -2.2 & 20.1 & 58.4 \\
\hline 1992 & -23.6 & -5.6 & 17.3 & -63.7 & -38.5 & -2.6 & 49.0 & 19.2 & -10.0 & 6.5 & 34.8 & -41.6 & -14.8 & 14.3 & 61.7 \\
\hline 1993 & -7.1 & -8.8 & -2.0 & -74.4 & -34.4 & -31.9 & -37.8 & 11.1 & 4.5 & 1.8 & 13.3 & -54.2 & -15.0 & -11.9 & -18.6 \\
\hline 1994 & -5.5 & -2.5 & 7.2 & -69.2 & -21.5 & -2.5 & -45.6 & 7.1 & -3.4 & -0.8 & & -66.1 & -19.9 & -4.4 & -42.4 \\
\hline 1995 & -6.6 & -10.6 & -38.7 & -36.8 & -1.2 & -0.6 & -53.7 & 8.5 & 1.2 & -3.4 & -27.5 & -25.5 & 6.4 & 7.1 & -38.5 \\
\hline 1996 & -5.6 & -14.7 & -53.3 & -38.4 & -6.2 & -16.3 & -54.7 & 3.7 & 4.2 & -4.7 & -44.6 & -29.9 & -0.6 & -8.3 & -42.9 \\
\hline 1997 & -3.4 & -10.2 & -65.4 & -62.2 & -15.6 & -23.2 & -68.7 & 0.0 & 3.5 & -2.7 & -51.9 & -47.4 & -4.6 & -10.6 & -51.8 \\
\hline 1998 & -6.7 & -10.7 & -76.4 & -75.9 & -18.6 & -30.4 & -58.0 & -1.5 & 0.6 & -2.8 & -61.9 & -59.1 & -6.4 & -15.8 & -41.9 \\
\hline 1999 & -3.8 & -14.3 & -59.2 & -72.6 & -9.9 & 9.3 & 12.5 & -4.3 & 2.0 & -8.9 & -52.4 & -64.5 & -6.0 & 8.7 & 12.8 \\
\hline 2000 & 3.6 & -2.1 & -44.4 & -38.7 & -2.8 & 3.5 & 16.8 & -13.0 & 0.1 & -5.0 & -45.8 & -40.5 & -6.6 & -2.1 & 9.7 \\
\hline 2001 & 11.8 & 2.3 & -39.3 & -15.4 & -6.3 & 0.5 & -8.2 & -11.0 & 6.8 & -1.4 & -39.6 & -18.6 & -8.6 & -3.7 & -11.3 \\
\hline 2002 & 15.2 & 9.7 & -3.4 & 56.3 & -2.0 & 7.0 & -10.4 & -16.3 & 6.6 & 2.4 & -10.8 & 43.7 & -8.4 & -1.6 & -16.5 \\
\hline 2003 & 15.1 & 15.9 & 13.0 & 40.8 & 4.4 & 8.7 & 0.2 & -17.7 & 2.2 & 4.0 & & 26.7 & -5.3 & -2.1 & -9.2 \\
\hline 2004 & 22.5 & 23.3 & 25.7 & 23.7 & 13.1 & 37.0 & 7.4 & -23.7 & 6.0 & 7.3 & 7.0 & 4.8 & -3.9 & 14.5 & -9.1 \\
\hline 2005 & 23.0 & 32.3 & 29.7 & 37.2 & 18.8 & 40.9 & 7.8 & -31.0 & 0.1 & 8.8 & 5.1 & 11.0 & -4.0 & 12.8 & -14.1 \\
\hline 2006 & 23.4 & 35.7 & 31.1 & 45.6 & 24.8 & 62.1 & 10.0 & -32.6 & -0.9 & 10.1 & 4.5 & 16.4 & -1.0 & 28.9 & -13.6 \\
\hline 2007 & 11.1 & 26.9 & 15.7 & 33.6 & 16.3 & 47.0 & -10.2 & -22.9 & -3.4 & 10.8 & 0.3 & 14.6 & 0.1 & 24.2 & -22.3 \\
\hline 2008 & 11.8 & 22.0 & 8.3 & 31.4 & 21.1 & 18.0 & -3.5 & -23.6 & -4.5 & 5.2 & -8.4 & 11.4 & -8.2 & 0.2 & -17.9 \\
\hline 2009 & 7.2 & 6.4 & 5.0 & 24.2 & 8.8 & 25.5 & 4.5 & -9.9 & -2.0 & -5.1 & -5.1 & 11.9 & -1.2 & 12.0 & -5.2 \\
\hline 2010 & 8.8 & 8.2 & -7.5 & 19.4 & 3.9 & 12.0 & -26.3 & -11.0 & -1.0 & -3.8 & -17.6 & 7.2 & -5.5 & 0.7 & -33.0 \\
\hline
\end{tabular}


Table 8: Undervaluation (e $>0$ and $r>0$ ) or overvaluation $(e<0$ and $r<0)$ for China, India, Korea, Thailand, Malaysia, Philippines and Indonesia (in \%)

\begin{tabular}{|c|c|c|c|c|c|c|c|c|c|c|c|c|c|c|}
\hline & \multicolumn{7}{|c|}{ Nominal Bilateral } & \multicolumn{7}{|c|}{ Real Effective } \\
\hline & CHN & $I N D$ & $K O R$ & THA & $M Y S$ & PHI & $I N S$ & CHN & $I N D$ & KOR & THA & MYS & PHI & INS \\
\hline 1982 & 29.9 & 10.3 & 17.2 & 26.2 & -32.7 & -28.7 & -44.9 & 33.7 & 2.9 & 7.5 & 15.6 & -24.8 & -30.2 & -45.8 \\
\hline 1983 & 25.6 & 19.6 & 26.8 & -27.2 & -19.4 & 3.1 & -49.8 & 25.4 & 4.1 & 8.3 & -34.1 & -22.5 & -10.4 & -57.1 \\
\hline 1984 & 12.9 & 23.8 & 21.2 & -7.1 & 5.0 & 45.3 & -1.6 & 5.7 & 7.9 & 3.6 & -18.4 & -7.6 & 25.1 & -15.2 \\
\hline 1985 & -42.6 & -5.1 & 8.1 & -9.3 & -3.0 & 46.3 & -16.8 & -48.7 & -10.7 & 1.0 & -12.9 & -6.6 & 34.7 & -21.0 \\
\hline 1986 & -1.1 & -1.3 & 25.2 & 26.2 & 3.7 & 73.6 & -37.3 & -15.2 & -11.0 & 10.6 & 12.5 & -5.3 & 53.6 & -42.7 \\
\hline 1987 & 27.2 & -5.1 & 25.4 & 6.1 & 15.5 & 38.0 & -8.3 & 13.0 & -10.7 & 14.0 & -0.3 & 5.5 & 26.2 & -12.5 \\
\hline 1988 & -12.3 & -21.9 & 16.0 & -16.4 & 1.9 & 22.2 & -18.5 & -8.2 & -18.2 & 14.0 & -9.5 & 2.6 & 19.8 & -13.8 \\
\hline 1989 & -26.0 & -21.9 & -7.8 & -24.3 & -9.6 & -9.6 & -18.7 & -18.6 & -15.9 & -1.9 & -12.9 & -1.6 & -3.3 & -11.6 \\
\hline 1990 & 25.2 & -22.4 & -15.5 & -50.3 & -12.4 & -23.9 & -25.8 & 27.3 & -18.0 & -9.0 & -30.2 & -2.9 & -15.2 & -18.7 \\
\hline 1991 & 15.0 & -0.6 & -26.9 & -47.7 & -26.9 & -8.2 & -34.3 & 24.9 & 10.6 & -11.2 & -22.1 & -2.5 & 3.2 & -18.4 \\
\hline 1992 & -5.3 & 12.0 & -23.9 & -36.6 & -21.7 & -15.0 & -22.3 & 7.4 & 23.8 & -7.7 & -14.1 & -0.7 & -0.5 & -7.1 \\
\hline 1993 & -33.7 & 13.8 & -22.3 & -32.6 & -22.0 & -33.8 & -18.5 & -21.0 & 27.0 & -5.5 & -10.5 & -0.6 & -12.6 & -2.8 \\
\hline 1994 & 17.3 & 25.1 & -11.6 & -15.5 & -8.9 & -14.2 & -2.1 & 18.6 & 19.9 & -12.3 & -12.5 & -3.6 & -12.3 & -5.1 \\
\hline 1995 & -7.4 & -3.2 & -19.7 & -26.8 & -17.8 & -15.1 & -16.5 & 0.8 & 4.8 & -8.5 & -9.5 & -0.4 & -3.9 & -6.6 \\
\hline 1996 & -9.9 & -4.1 & -29.9 & -27.5 & -8.1 & -18.9 & -9.0 & 0.7 & 1.6 & -18.6 & -13.3 & -0.6 & -8.5 & -2.7 \\
\hline 1997 & 7.1 & 2.2 & -19.8 & -4.4 & -8.6 & -16.8 & 11.9 & 14.5 & 9.2 & -9.3 & 1.9 & -0.6 & -5.3 & 16.5 \\
\hline 1998 & 7.4 & -15.0 & 11.4 & 20.5 & 0.5 & -1.1 & 28.3 & 16.0 & -6.3 & 15.0 & 17.9 & 1.3 & 3.8 & 27.6 \\
\hline 1999 & 1.8 & 3.5 & 1.8 & 16.9 & 6.9 & -11.9 & 2.0 & 8.5 & 5.4 & 3.2 & 11.9 & 1.4 & -6.1 & 3.8 \\
\hline 2000 & 8.8 & -2.0 & -3.1 & 13.8 & 7.5 & -1.5 & 14.1 & 6.1 & -5.8 & -5.9 & 4.4 & -1.2 & -4.1 & 8.0 \\
\hline 2001 & 5.2 & 13.7 & -4.2 & 6.5 & 0.8 & -3.4 & 20.6 & 1.0 & 9.7 & -5.9 & 0.8 & -2.1 & -4.5 & 14.6 \\
\hline 2002 & 16.4 & 30.6 & 0.7 & 10.4 & 6.2 & 3.0 & 20.1 & 7.1 & 21.4 & -5.5 & 0.5 & -2.3 & -3.5 & 11.0 \\
\hline 2003 & 23.0 & 29.1 & 6.7 & 16.9 & 14.4 & 8.4 & 22.9 & 8.4 & 17.6 & -2.7 & 2.7 & -0.4 & -1.7 & 11.7 \\
\hline 2004 & 25.1 & 15.4 & 22.6 & 23.1 & 23.8 & 20.5 & 19.5 & 7.1 & -2.6 & 2.7 & 1.1 & -0.8 & 0.2 & 0.9 \\
\hline 2005 & 41.8 & 2.1 & 23.0 & 16.0 & 33.2 & 26.1 & 24.3 & 15.9 & -21.3 & -2.8 & -5.7 & -0.2 & -1.0 & -1.8 \\
\hline 2006 & 47.4 & 14.7 & 21.5 & 30.0 & 37.0 & 32.6 & 38.2 & 19.2 & -12.0 & -5.7 & -0.4 & 0.5 & 1.9 & 8.5 \\
\hline 2007 & 38.6 & 9.9 & 15.6 & 34.6 & 29.9 & 28.4 & 32.2 & 21.2 & -8.1 & -3.1 & 7.0 & 1.7 & 5.5 & 11.1 \\
\hline 2008 & 34.5 & -0.9 & 16.5 & 24.8 & 34.5 & 23.8 & 25.8 & 16.2 & -17.2 & -2.4 & 1.5 & 4.4 & 2.6 & 4.9 \\
\hline 2009 & 22.4 & -3.8 & 19.5 & 28.8 & 20.2 & 25.0 & 25.7 & 10.8 & -12.9 & 5.8 & 10.5 & 3.5 & 9.8 & 12.2 \\
\hline 2010 & 23.8 & -4.6 & 11.3 & 16.4 & 16.6 & 19.0 & 26.7 & 11.4 & -14.6 & -0.6 & 2.8 & 2.0 & 5.2 & 12.8 \\
\hline
\end{tabular}




\section{Appendix 7: Comparison with other approaches}

We compare our own misalignments' estimations with other approaches using FEER or BEER methodology. First, a comparison with Cline's estimates is interesting as, in both cases, the FEER framework is used. Cline's model has 35 countries, a simpler analysis of the foreign trade for each country and no structural approach of the equilibrium current account. Instead, it is simply supposed that external imbalances should not exceed 3\% of GDP (in absolute value) in the medium term, which allows building a scenario of current account targets for the 30 nonoil exporting countries.

Table 9: Comparison with Cline's OCI estimates (in \%)

\begin{tabular}{|c|c|c|c|c|c|c|c|c|c|c|c|c|}
\hline & \multicolumn{6}{|c|}{ Real Effective } & \multicolumn{6}{|c|}{ Nominal Bilateral } \\
\hline & \multicolumn{2}{|c|}{2008} & \multicolumn{2}{|c|}{2009} & \multicolumn{2}{|c|}{2010} & \multicolumn{2}{|c|}{2008} & \multicolumn{2}{|c|}{2009} & \multicolumn{2}{|c|}{2010} \\
\hline & Our's & Cline & Our's & Cline & Our's & Cline & Our's & Cline & Our's & Cline & Our's & Cline \\
\hline$U S A$ & -23.6 & -7.8 & -9.9 & -5.7 & -11.0 & -7.8 & - & - & - & - & - & - \\
\hline China & 16.2 & 12.6 & 10.8 & 29.6 & 11.4 & 13.5 & 34.5 & 23.4 & 22.4 & 40.7 & 23.8 & 24.2 \\
\hline India & -17.2 & -2.1 & -12.9 & -12.0 & -14.6 & -1.8 & -0.9 & 7.3 & -3.8 & -1.5 & -4.6 & 7.7 \\
\hline Brazil & -8.4 & -0.4 & -5.1 & -27.8 & -17.6 & -5.9 & 8.3 & 5.8 & 5.0 & -15.4 & -7.5 & 0.0 \\
\hline Korea & -2.4 & -2.0 & 5.8 & -16.5 & -0.6 & -1.8 & 16.5 & 10.0 & 19.5 & -3.0 & 11.3 & 9.5 \\
\hline
\end{tabular}

(Source: Cline, 2008; Cline and Williamson, 2008, 2009, 2010; authors' calculations, forecast for 2010)

(A positive number indicates an undervaluation. Conversely, a negative number indicates an overvaluation)

Our results are close to those of Cline, in real effective terms, with some divergence regarding the dollar in 2008, which can be understood, but has an incidence on all the estimated nominal bilateral misalignments against the dollar (table 7). This discrepancy in 2008 is mainly explained by differences in the US current account target. In a previous estimation for 2008, we had a target close to $-3 \%$ of GDP (as in Cline's work) and results gave a more limited overvaluation of $-11.1 \%$ for the dollar in 2008. However, the actual estimation with an overvaluation of -24\% seems plausible as the US current deficit was still -5\% of GDP in 2008. For 2009 and 2010, the results are very close.

For emerging countries, the results are globally convergent, on the whole period, with some exceptions which can be explained by differences in the current account targets. For example, our estimates give more overvalued currency for India relatively to those of Cline. For this country, Cline uses a target of $-3 \%$ of GDP. Conversely, our econometric estimates give a target of $-1 \%$, which increases overvaluation since the current account target is relatively higher.

At first glance, except for two main countries, India and Brazil, and some specific periods, the FEER and BEER's misalignments present large similarities. On the whole, BEERs' misalignments are more important than FEERs' ones, which is consistent with the long run nature of the equilibrium in the BEER approach ${ }^{6}$.

This diagnosis can be completed by two indicators, the absolute average deviation (equal to the average difference between FEERs and BEERs) and the correlation coefficient between misalignments given by both approaches. The absolute average deviation is equal to $16 \%$ for all the countries, but is smaller for two third of them. Similarly, the correlation coefficient is above 0.5 for two third of the countries (table 8). The FEER and BEER give more divergent estimations for the three main emerging countries, China, Brazil and India, but are more convergent for industrialized countries and also for Mexico, Chile, Malaysia and Indonesia.

\footnotetext{
${ }^{6}$ The series of BEERs' misalignments come from Béreau, Lòpez-Villavicencio and Mignon (2010).
} 
Absolute average deviation

\begin{tabular}{|c|c|c|c|}
\hline & & Below Average & Above Average \\
\hline \multirow{2}{*}{ Correlation } & Above $50 \%$ & $\begin{array}{c}\text { USA, Euro area, Japan, Mexico, } \\
\text { Korea, Indonesia, Malaysia, } \\
\text { Chile }\end{array}$ & Argentina, Colombia, Uruguay \\
\hline & Below $50 \%$ & UK, Philippines, Thailand & China, Brazil, India \\
\hline \multicolumn{4}{|c|}{$\begin{array}{l}\text { For a better understanding of the FEER and BEER divergence, it can be recalled that the BEER } \\
\text { is rather stable in the long run and, consequently, BEERs' misalignments are mainly deviations } \\
\text { between real exchange rates and an average value. Generally, real appreciation above this mean } \\
\text { value leads to overvaluation and, inversely, real depreciation leads to undervaluation. On the } \\
\text { opposite, the FEER is linked to a rather stable current account balance. FEERs' misalignments } \\
\text { reflect mainly deviations between observed and equilibrium current balance. Generally, a rising } \\
\text { current account above the equilibrium value leads to undervaluation and, inversely, a decreasing } \\
\text { current account leads to overvaluation. Consequently, FEER and BEER misalignments are } \\
\text { consistent when real exchange rate and current account are closely connected. As an illustration, } \\
\text { we calculate the linear correlation coefficient between current account and real effective } \\
\text { exchange rate. When the correlation is strong, the misalignments computed by the FEERs and } \\
\text { BEERs follow the same path. }\end{array}$} \\
\hline
\end{tabular}

Appendix 8: Panel unit root test for the determinants of the real effective misalignments in absolute value

\begin{tabular}{|c|c|c|}
\hline & Level & First Difference \\
\hline & IPS & IPS \\
\hline$A E R M^{1}$ & $-6.42 * * *$ & $-18.08 * * *$ \\
\hline$E R M^{2}$ & $-6.62 * * *$ & $-14.99 * * *$ \\
\hline OPEN & 4.62 & $-12.25^{* * *}$ \\
\hline ACRMAN & 3.80 & $-12.60 * * *$ \\
\hline$X R E G$ & $-2.15^{* *}$ & $-2.97 * * *$ \\
\hline RKAOPEN & $-12.45^{* * *}$ & $-13.00 * * *$ \\
\hline$E E R$ & $-5.13 * * *$ & $-6.46 * * *$ \\
\hline
\end{tabular}

(Source: authors' calculation)

$(* * *=$ Significant at $1 \%, * *=$ significant at $5 \%, *=$ significant at $10 \%$ using the test statistic Im Pesaran Shin; the rejection of the null hypothesis (of the presence of unit root), leads us to reject non-stationarity of the series.)

Notes: (1) The acronym AERM stands for the absolute value of exchange rate misalignment in real effective terms.

Notes: (2) The acronym ERM stands for exchange rate misalignment in real effective terms. 


\section{References}

[1] Ahearne, A., Cline, W.R., Lee, K.T., Park, Y.C., Pisani-Ferry, J., Williamson, J., 2007. Global imbalances: Time for action, Policy Brief 07-4, March, Peterson Institute for International Economics, Washington, DC.

[2] Bénassy-Quéré, A., Béreau, S., Mignon, V., 2009. Taux de change d'équilibre : une question d'horizon, Revue Économique 60, mars, Presses de Sciences-Po, 657-666.

[3] Béreau, S., A. Lòpez-Villavicencio and V. Mignon, 2010. Nonlinear adjustment of the real exchange rate towards its equilibrium value: A panel smooth transition error correction modelling, Economic Modelling 27, 404-416.

[4] Borowski, D., Couharde, C., 2003. The exchange rate macroeconomic balance approach: New methodology for the euro, the dollar, the yen and the pound, Open Economies Review 14, Kluwer Academic Publishers, 169-190.

[5] Bouveret, A., Mestiri, S., Sterdyniak, H., 2006. La valeur du yuan. Les paradoxes des taux de change d'équilibre, Revue de l'OFCE 98, juillet, Presse de Science-Po, 98-127.

[6] Bouveret, A., Sterdyniak, H., 2005. Les modèles de taux de change. Équilibre de long terme, dynamique et hystérèse, Revue de l'OFCE 93, Presses de Sciences-Po, 243-286.

[7] Carton, B., Hervé, K., 2010. Estimation of consistent multi-country FEERs, CEPII Working Paper 2010-02, February.

[8] Chauvin, S., Lemoine, F., 2005. L'économie Indienne : changements structurels et perspectives à long-terme, CEPII Working Paper 2005-04, avril.

[9] Chinn, M.D., Prasad, E.S., 2003. Medium term determinants of current accounts in industrial and develloping countries: an empirical exploration, Journal of International Economics 59, Elsevier, 47-76.

[10] Chinn, M.D., Ito, H., 2008. A New Measure of Financial Openness, Journal of Comparative Policy Analysis 10, 309-322.

[11] Clark, P.B., MacDonald, R., 1998. Exchange rates and economics fundamentals: a methodological comparison of BEERs and FEERs, Working Paper 98/67, March, International Monetary Fund, Washington, DC.

[12] Cline, W.R., 2008. Consistent estimates of fundamental equilibrium exchange rates, Working Paper 08-6, July, Peterson Institute for International Economics, Washington, DC.

[13] Cline, W.R., Williamson, J., 2008. New estimates of fundamental equilibrium exchange rates, Policy Brief 08-7, July, Peterson Institute for International Economics, Washington, DC.

[14] Cline, W.R., Williamson, J., 2009. 2009 Estimates of fundamental equilibrium exchange rates, Policy Brief 09-10, June, Peterson Institute for International Economics, Washington, DC.

[15] Cline, W.R., Williamson, J., 2010. Notes on equilibrium exchange rates: january 2010, Policy Brief 10-2, January, Peterson Institute for International Economics, Washignton, DC.

[16] Cline, W.R., Williamson, J., 2010. Estimates of fundamental equilibrium exchange rates, May 2010, Policy Brief 10-15, June, Peterson Institute for International Economics, Washington, DC.

[17] Collignon S., Pisani-Ferry J., Park, Y.C. (Eds), 1999. Exchange Rate Policies in Emerging Asian Countries, Routledge, London.

[18] Driver, R.L., Westaway, P.F., 2004. Concepts of equilibrium exchange rates, Bank of England Working Paper 248, Bank of England.

[19] Faruqee, H., Isard, P. (Eds), 1998. Exchange rate assessment: Extensions to the macroeconomic balance approach, IMF Occasional Paper 167, International Monetary Fund, Washington, DC. 
[20] Gerlach, S., Yiu, M.S., 2004. Estimating output gaps in asia: A cross-country study, Journal of the Japanese and International Economies 18, March, Elsevier, 115-136.

[21] Ito, T., Isard, P., Symansky, S., Bayoumi, T., 1996. Exchange rate movements and their impact on trade and investment in the APEC region, IMF Occasionnal Paper 145, International Monetary Fund, Washington, DC.

[22] Im, K., Pesaran, M. H., Shin, Y. (2003). Testing for unit roots in heterogeneous panels. Journal of Econometrics 115(1), Elsevier, 53-74.

[23] Jeong, S.-E., Mazier, J., 2003. Exchange rate regimes and equilibrium exchange rates in East Asia, Revue économique 54, September, Presses de Sciences Po, 1161-1182.

[24] Jeong, S.-E., Mazier, J., Saadaoui, J., 2010. Exchange rate misalignments at world and European level: a FEER approach, Économie Internationale 121, La Documentation Française, 25-58.

[25] Kim, Y.C., 1999. An external sector model of korean economy, The Bank of Korea Economic Papers 2, The Bank of Korea.

[26] Korhonen, I., Ritola, M., 2009. Renminbi misaligned - Results from meta-regressions, BOFIT Discussion Papers 13/2009, Bank of Finland, Institute for Economies in Transition.

[27] Lee, J., Milesi-Ferreti G.M., Ostry J.D., Prati A., Ricci L.A., 2008. Exchange rate assessments: CGER methodologies, IMF Occasional Papers 261, April, International Monetary Fund, Washington, DC.

[28] Lopez-Villavicencio, A., Mazier, J., Saadaoui, J., 2010. Temporal dimension and equilibrium exchange rate: A FEER / BEER comparison, CEPN-CNRS Working Paper 2010-14.

[29] Pain, N., Mourougane, A., Sédillot, F., Le Fouler, L., 2005. The new OECD international trade model, OECD Working paper $\mathrm{n}^{\circ} 440$, August, Organisation for Economic Cooperation and Development.

[30] Salama, P., 2009. Argentine, Brésil, Mexique, face à la crise internationale, Revue Tiers Monde 197, Armand Colin, 183-202.

[31] Senhadji, A., 1998. Time-series estimation of structural import demand equations: a cross-country analysis, IMF Staff Papers 45, Palgrave Macmillan Journals, 236-268.

[32] Senhadji, A., Montenegro, C.E., 1999. Time series analysis of export demand equations: a cross-country analysis. IMF Staff Papers 46, International Monetary Fund, 259-273.

[33] Stein, J.L., Allen, P.R. et al., 1997. Fundamental determinants of exchange rates, Oxford University Press.

[34] Williamson, J., 1983. The Exchange Rate System, $1^{\text {st }}$ edition, $2^{\text {nd }}$ edition 1985 , Institute for International Economics, Washington, DC. 